\title{
Investigation of structural and luminescence properties of nanocrystalline tungsten-incorporated molybdenum disulphide ternary compounds: an experimental and DFT study
}

\author{
D KALITA $^{1, *}$, L CHETIA $^{1,2}$, P CHETRI $^{3}$ and G A AHMED ${ }^{1}$ \\ ${ }^{1}$ Department of Physics, Tezpur University, Napaam 784028, India \\ ${ }^{2}$ Department of Physics, PDUAM, Dalgaon, Darrang 784116, India \\ ${ }^{3}$ Department of Physics, D.R. College, Golaghat 784028, India \\ *Author for correspondence (kalitadeb@gmail.com)
}

MS received 29 August 2018; accepted 15 October 2018; published online 25 April 2019

\begin{abstract}
The present manuscript reports the synthesis of tungsten-incorporated molybdenum disulphide ternary compounds in particle form at the nanoscale using existing solid state reactions, followed by ultrasonication and a density functional theory (DFT) investigation of the compound system. The effect of $\mathrm{W}$ in the $\mathrm{W}$-inserted $\mathrm{MoS}_{2}$ ternary compound system is the subject of current research. A comparative study shows enhanced photoluminescence (PL) at room temperature in the as-synthesized transition metal dichalcogenide (TMD) ternary compound. The compositional and structural characterization studies of the materials are performed using XRD, SEM, EDX, TEM and Raman spectroscopy. We have observed that a combination of $\mathrm{W}$ and $\mathrm{S}$ leads to better crystallinity than the combination of Mo and $\mathrm{S}$ in the compound system. The high band gap (BG) energy also confirms the nanoscale dimension of the material system which may be attributed to the formation of excitonic states from spin splitting and band nesting effects. A theoretical investigation of the effect of W in the $\mathrm{MoS}_{2}$ system using DFT also reveals that insertion of W leads the system toward a direct BG semiconductor (SC). Multiple BGs of the material in the visible light range as found by UV-Visible (UV-Vis) spectroscopy, suggest applicability of these materials in luminescence devices and photocatalytic activity.
\end{abstract}

Keywords. Semiconductor; photoluminescence; density functional theory; band nesting.

\section{Introduction}

Graphene, though a two-dimensional material with incredible physical and electrical properties, however, has application problems in energy conversion issues due to its non-existing energy band gap (BG). Growing curiosity in the study of optical properties and electronic properties of two-dimensional transition metal dichalcogenides (TMDs) has been observed in recent years because of its finite BG energy [1-4]. TMDs are considered to be the successor of graphene in recent years and studied extensively. The optical properties of such layered X-M-X structured TMDs (where M $=$ Mo, W, V, Nb, $\mathrm{Ta}, \mathrm{Ti}, \mathrm{Zr}$ and $\mathrm{Hf}$ and $\mathrm{X}=\mathrm{S}, \mathrm{Se}$ and $\mathrm{Te}$ ) show a drastic change depending on the number of stacked layers [5-7]. Monolayers of TMDs are reported to have a finite direct optical BG energy [4,8,9]. Among all the TMDs, $\mathrm{MoS}_{2}$ and $\mathrm{WS}_{2}$ are studied most as they have direct $\mathrm{BGs}$ in the visible range and luminescence properties which demand applicability in electronics and optoelectronic devices such as transistors, batteries, solar cells, etc. [4,10-12]. The synthesis of layered $\mathrm{MoS}_{2} /$ graphene $\left(\mathrm{MoS}_{2} / \mathrm{G}\right)$ composites, the use of $\mathrm{MoS}_{2} / \mathrm{TiO}_{2}$ nanocomposites in a photovoltaic (PV) cell, application of a ITO- $\mathrm{MoS}_{2}-\mathrm{Au}$ stacked structure in PV cells, photocatalytic activity of different composites of $\mathrm{MoS}_{2}$ and $\mathrm{WS}_{2}$ with
$\mathrm{TiO}_{2}, \mathrm{CdS}$, graphene, etc., have been reported in recent years [12-15].

Both $\mathrm{MoS}_{2}$ and $\mathrm{WS}_{2}$ have a similar structure (trigonal prismatic $\left(\mathrm{Mo}^{\mathrm{IV}}\right.$ or $\left.\mathrm{W}^{\mathrm{IV}}\right)$ and pyramidal $\left(\mathrm{S}^{-2}\right)$ ) and hence, they have minimum lattice mismatch in their compounds. Through TMDs, 3d block metal intercalation of TMDs and composites of these materials are explored extensively worldwide, but the detailed study of ternary compounds of Mo (4d block) and W (5d block) is extremely rare. The $\mathrm{H}_{2}$ evolution catalysis and superconducting nature of some ternary TMDs in the form of nanotubes and nanosheets are reported by few researchers [16-21]. In this paper, we have reported the synthesis of MoW-disulphide ternary compounds with different Mo:W molar ratios in particle form at the nanoscale using solid state reactions and provide a comparative analysis of their morphology and optical properties with that of the as-synthesized $\mathrm{MoS}_{2}$ and $\mathrm{WS}_{2}$ nanoparticles (NPs). Here, a novel approach for utilizing the solid state reaction mechanism for the synthesis of ternary TMDs is achieved. Different characteristic techniques e.g., X-ray diffraction (XRD), Raman spectroscopy, scanning electron microscopy (SEM) and energy dispersive X-ray (EDX) spectroscopy are employed to study the morphology of the as-synthesized materials. The optical properties of the 
materials are investigated using UV-Visible spectroscopy and photoluminescence (PL) spectroscopy. An enhancement in luminescence is observed in the W-incorporated $\mathrm{MoS}_{2}$ ternary compound having a W:Mo molar ratio equals to one, indicating that it can be a good material for luminescence devices. We have also performed density functional theory (DFT) simulation to study the effect of the addition of W into the $\mathrm{MoS}_{2}$ system and investigated total density of states (TDOS) and partial density of states (PDOS) along with the band structure of the systems having different combinations of W, Mo and S.

\section{Details of characterization, computational techniques employed and material synthesis processes}

In the present work, the XRD analysis of the as-synthesized powdered samples is performed using an X-ray diffractometer (Rigaku Miniflex) with $\mathrm{CuK} \alpha$ radiation $(\lambda=1.5405 \AA)$ in the $2 \theta$ range from 10 to $70^{\circ}$. EDX spectra of the samples are obtained using an INCAX-sight EDX detector (JEOL JSM-6390LV). The UV-Visible spectral analyses of all the asprepared samples are performed using a UV-Visible absorption spectrometer (UV 2450, Shimadzu Corporation). Raman spectra are recorded using a LabRam HR laser micro Raman system and PL is obtained using an F-2700 FL spectrophotometer.

In DFT calculation, a periodic cell is constructed with $\left(\mathrm{MoS}_{2}\right)_{8}$ molecules, and then, we insert $\mathrm{W}$ into it to make $\mathrm{Mo}_{8} \mathrm{WS}_{16}$. We are also interested to check how the system behaves when both Mo and $\mathrm{W}$ are in equal ratio, so we increase the content of $\mathrm{W}$ and construct $\mathrm{Mo}_{8} \mathrm{~W}_{8} \mathrm{~S}_{16}$. All these structures are optimized and made free from any symmetry constrains. These structures are allowed to obtain a minimum energy configuration by relaxing all the atoms in all directions. We have performed density functional calculations using generalized gradient approximation (GGA) functional with Perdew-Burke-Ernzerhof (PBE) to describe the electron-electron exchange and correlation effects. The DFT equations are solved via the projector-augmented wave (PAW) method using plane wave basis set as implemented in the Vienna $a b$ initio simulation package (VASP) and interfaced with the MedeA technology platform. The minimum energy state is computed by varying the internal position of atoms until the residual force is $0.01 \mathrm{eV} \AA^{-1}$. The electronic wave functions are expanded using a plane-wave basis set with a cut-off energy of $480 \mathrm{eV}$. The Brillouin-zone integration for geometry optimizations and electronic property calculations is performed by using a $3 \times 3 \times 5$ Monkhorst-Pack $k$-point grid for the structure. A Methfessel-Paxton type of smearing is used with a smearing width of $0.2 \mathrm{eV}$. A real space projection operator is used as the system contains large number of atoms.

Different synthesis processes have been reported to synthesize a monolayer to few layers of TMDs [4,5,22-27]. In this work, the syntheses of $\mathrm{MoS}_{2}, \mathrm{WS}_{2}$ and MoW-disulphide

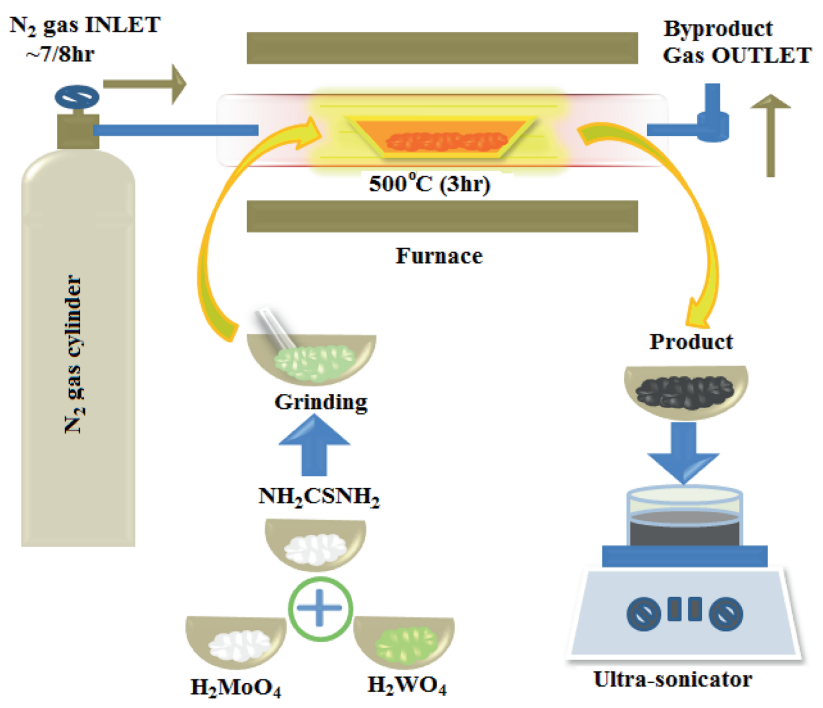

Figure 1. Schematic of the experimental set-up for material synthesis. In the synthesis process, the powdered raw materials are mixed thoroughly and heated at $500^{\circ} \mathrm{C}$ for $3 \mathrm{~h}$, followed by cooling at room temperature in a $\mathrm{N}_{2}$ gas environment inside a furnace to produce the final product.

compounds are performed using the solid state reactions described in equations $(1,2,3)[22,23]$ :

$$
\begin{aligned}
\mathrm{H}_{2} \mathrm{MoO}_{4} & +48 \mathrm{NH}_{2} \mathrm{CSNH}_{2} \underset{\mathrm{N}_{2}}{\stackrel{500^{\circ} \mathrm{C}}{\longrightarrow}} \mathrm{MoS}_{2}, \\
\mathrm{H}_{2} \mathrm{WO}_{4} & +48 \mathrm{NH}_{2} \mathrm{CSNH}_{2} \underset{500^{\circ} \mathrm{C}}{\stackrel{\mathrm{N}_{2}}{\longrightarrow}} \mathrm{WS}_{2}, \\
\mathrm{H}_{2} \mathrm{MoO}_{4} & +\mathrm{H}_{2} \mathrm{WO}_{4} \\
& +48 \mathrm{NH}_{2} \mathrm{CSNH}_{2} \underset{\mathrm{N}_{2}}{\stackrel{500^{\circ} \mathrm{C}}{\longrightarrow}} \mathrm{MoW} \text {-disulphide. }
\end{aligned}
$$

For the material synthesis purpose, commercially available molybdic acid (Rankem (M0240)), tungstic acid (Himedia (RM6308-100G)) and thiourea (Rankem (T0050)) are chosen as the raw materials. The chemicals are at first separately ground mildly using a mortar and pestle to make fine powder of each chemical and are weighed separately using a chemical balance (Denver Instrument). These are then mixed with an appropriate molar ratio in a silica combustible boat and kept inside the furnace. The furnace is then set at $500^{\circ} \mathrm{C}$ for $3 \mathrm{~h}$ with a continuous supply of $\mathrm{N}_{2}$. After $3 \mathrm{~h}$ of continuous heating, the product is left to cool in a $\mathrm{N}_{2}$ environment for another $4-5 \mathrm{~h}$ until the furnace is cooled to room temperature. The blackish product (flakes) is next collected for purification and further investigation. A schematic of the set-up used for this synthesis is shown in figure 1.

For the synthesis of a MoW-disulphide ternary compound, we have taken molybdic acid and tungstic acid with excess thiourea as the raw material and their percentage compositions were estimated using SEM-EDX spot analysis. We have named the ternary compound as MoW-disulphide1 in which 

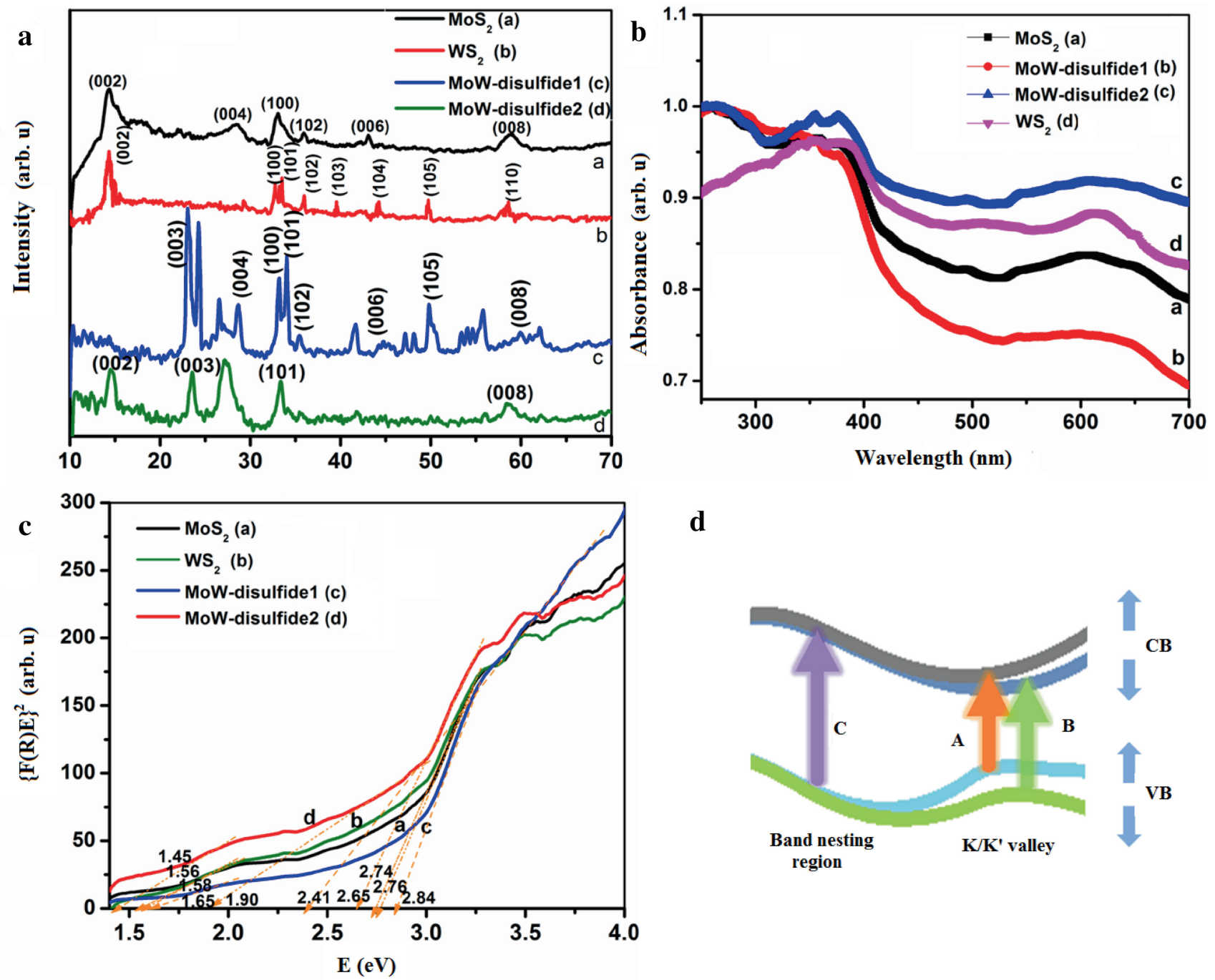

Figure 2. (a) XRD pattern of all the prepared samples showing different crystal planes, (b) UV-Vis absorption spectra of (a) MoS 2 , (b) $\mathrm{WS}_{2}$, (c) MoW-disulphide1 and (d) MoW-disulphide2 in the illumination range from 200 to $700 \mathrm{~nm}$, (c) KM plot of the as-synthesized materials to determine the optical energy BG values and (d) schematic of A, B and C excitonic bands to band transitions.

the Mo:W molar ratio is 1:1 and MoW-disulphide2 in which the Mo:W molar ratio is $10: 1$.

To ascertain that the as-prepared $\mathrm{MoS}_{2}$ and MoW-disulphide samples do not contain oxides e.g., $\mathrm{MoO}_{3}$ and other similar water soluble impurities, the samples are cleaned with warm distilled water at $70^{\circ} \mathrm{C}$ for $1 \mathrm{~h}$ to remove the water soluble contents and are centrifuged for $12 \mathrm{~min}$ at $6000 \mathrm{rpm}$. The coloured water content is pipetted out and the residue remained at the bottom. This cleaning process is repeated until the water becomes clear. The final water content is removed by a pipette and then the samples are dried at $70^{\circ} \mathrm{C}$ for $\sim 12 \mathrm{~h}$. The dry product is then grinded uniformly using a mortar and pestle to make fine powder. Thereafter, the powder is mixed with distilled water, stirred in a magnetic stirrer and sonicated several hours in $\mathrm{N}_{2}$ environment. This process breaks down the larger particles into nanoscale dimension.

\section{Results and discussion}

\subsection{Experimental section}

The different crystal planes in the XRD plots in figure $2 \mathrm{a}$ revealed the crystallinity of the materials. The prominent peaks and various crystal planes in plot (a) are characteristic of $\mathrm{MoS}_{2}$ revealing the formation of a hexagonal structure of the crystals. For the $\mathrm{MoS}_{2}$ sample, XRD peaks at $2 \theta$ equal to $14.24,28.36,33.01,35.83,42.98,58.71$ and $58.90^{\circ}$ correspond to the Millar crystal planes (002), (004), (100), (102), (006), (110) and (008), respectively, when compared with JCPDS no. 75-1539 (PCPDFWIN v. 2.02). The XRD peaks at $2 \theta$ values $14.36,32.77,33.59,35.94,39.60,44.29,49.79$ and $58.49^{\circ}$ in plot (b) correspond to (002), (100), (101), (102), (103), (104), (105) and (110) planes, respectively, of the $\mathrm{WS}_{2}$ sample when compared with JCPDS no. 84-1398. However, 
Table 1. 2e, $d$-spacing values and corresponding Millar planes for the MoW-disulphide1 compound.

\begin{tabular}{|c|c|c|c|c|c|c|c|c|}
\hline $2 \theta\left(^{\circ}\right)$ & 23.12 & 28.75 & 33.17 & 34.17 & 35.49 & 44.57 & 49.76 & 59.84 \\
\hline$d$-Spacing $(\AA)$ & 3.85 & 3.10 & 2.69 & 2.62 & 2.53 & 2.03 & 1.83 & 1.54 \\
\hline Miller plane & $(003)$ & $(004)$ & (100) & (101) & (102) & (006) & (105) & (008) \\
\hline
\end{tabular}

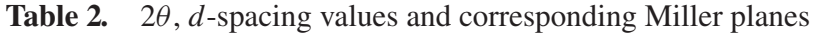
for the MoW-disulphide2 compound.

\begin{tabular}{|c|c|c|c|c|}
\hline $2 \theta\left(^{\circ}\right)$ & 14.52 & 23.53 & 33.41 & 59.01 \\
\hline$d$-Spacing $(\AA)$ & 6.10 & 3.78 & 2.68 & 1.56 \\
\hline Miller plane & (002) & (003) & (101) & (008) \\
\hline
\end{tabular}

the XRD patterns as shown by plots (c) and (d) in figure $2 \mathrm{a}$ of the compound MoW-disulphide samples are quite different from those of $\mathrm{MoS}_{2}$ and $\mathrm{WS}_{2}$ indicating the possible formation of new bonds in the compound structure of Mo and W. However, the XRD pattern of the MoW-disulphide2 sample resembles that of $\mathrm{MoS}_{2}$ due to the dominant effect of higher content of Mo element than W. The possible Miller planes correspond to $2 \theta$ values and respective $d$-spacing values in the ternary compound NPs are tabulated in tables 1 and 2. The $d$-spacing values are obtained from the XRD peaks using Bragg's law described in equation (4) as

$$
2 d \sin \theta=n \lambda,
$$

where $d, \theta, n$ and $\lambda$ represent the crystal plane spacing, Bragg's angle, order of diffraction and wavelength of Xray used in XRD characterization, respectively. We have also plotted the simulated powdered XRD pattern for $\mathrm{MoS}_{2}$ and
$\mathrm{WS}_{2}$ samples in comparison with the experimentally obtained XRD patterns in figure $3 \mathrm{a}$ and $\mathrm{b}$. The simulation is performed using the standard software VESTA 3 (visualization for electronic and structural analysis, version 3) [28]. It is obvious that experimentally synthesized materials have impurities and show deviations, but our experimental XRD plots for $\mathrm{MoS}_{2}$ and $\mathrm{WS}_{2}$ show similarity with the simulated one to a great extent as shown in figure $3 a$ and $b$.

The average crystallite sizes $(L)$ of $\mathrm{MoS}_{2}, \mathrm{WS}_{2}, \mathrm{MoW}$ disulphide1 and MoW-disulphide2 are calculated using the Debye-Scherrer formula [29] and found to be $\sim 11.07$, $13.02,22.02$ and $18.30 \mathrm{~nm}$, respectively. The increase in the crystallite size in MoW-disulphide1 reflects that $\mathrm{W}$ forms a better crystal with S compared to Mo. Because of the higher Mo:W ratio in MoW-disulphide2, the crystallite size again decreases as the concentration of Mo increases. Therefore, it reaffirms the fact that the combination of $\mathrm{W}$ and $\mathrm{S}$ leads to better crystallinity than the combination of Mo and $\mathrm{S}$.

We have also studied TEM to analyse the crystal planes present in the as-prepared samples. The TEM images in figure $4 \mathrm{a}-\mathrm{d}$ show different Millar planes in the as-prepared $\mathrm{MoS}_{2}, \mathrm{WS}_{2}, \mathrm{MoW}$-disulphide1 and MoW-disulphide2 compound NPs. TEM analysis confirms that the NPs are polycrystalline in nature. For the $\mathrm{MoS}_{2}$ plane, spacing of 0.61 and $0.28 \mathrm{~nm}$ in figure $4 \mathrm{a}$ corresponds to the crystallographic plane (002) and (100), respectively. The crystal plane
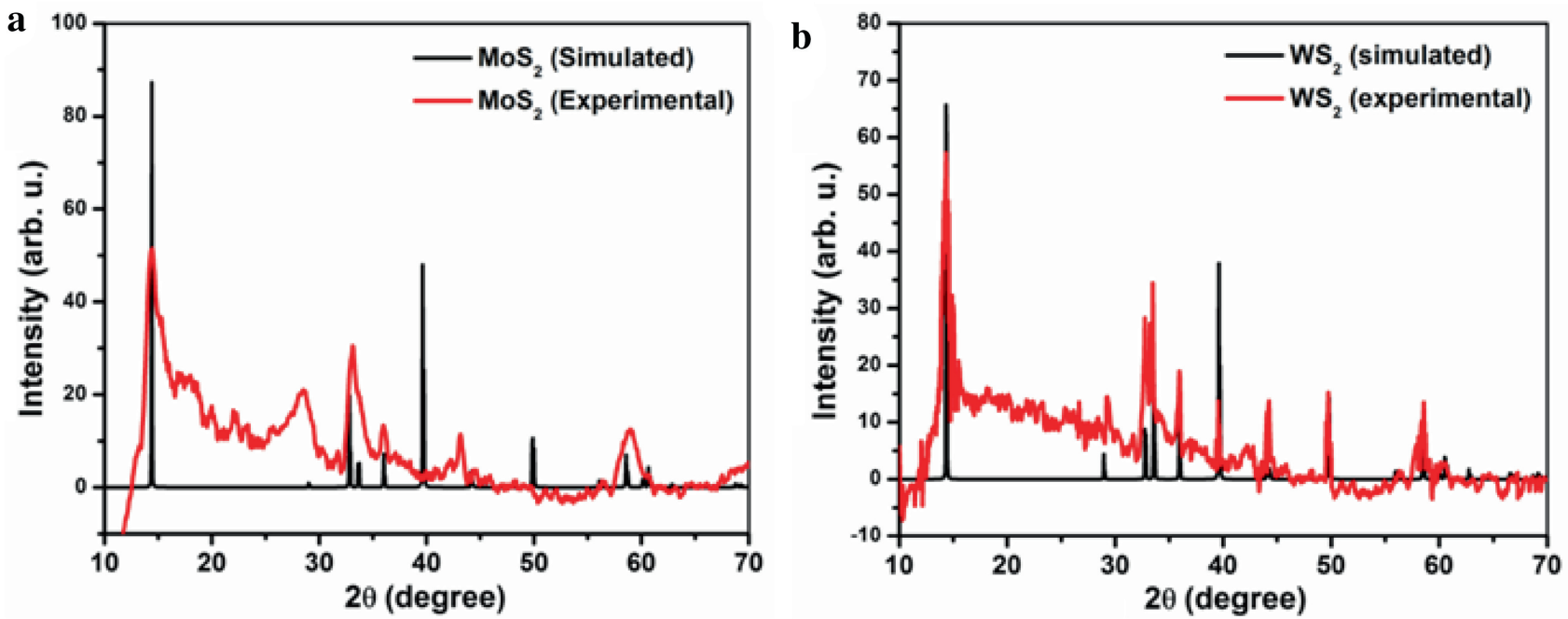

Figure 3. Comparison of simulated and experimental XRD patterns for (a) $\mathrm{MoS}_{2}$ and (b) $\mathrm{WS}_{2}$ sample. 

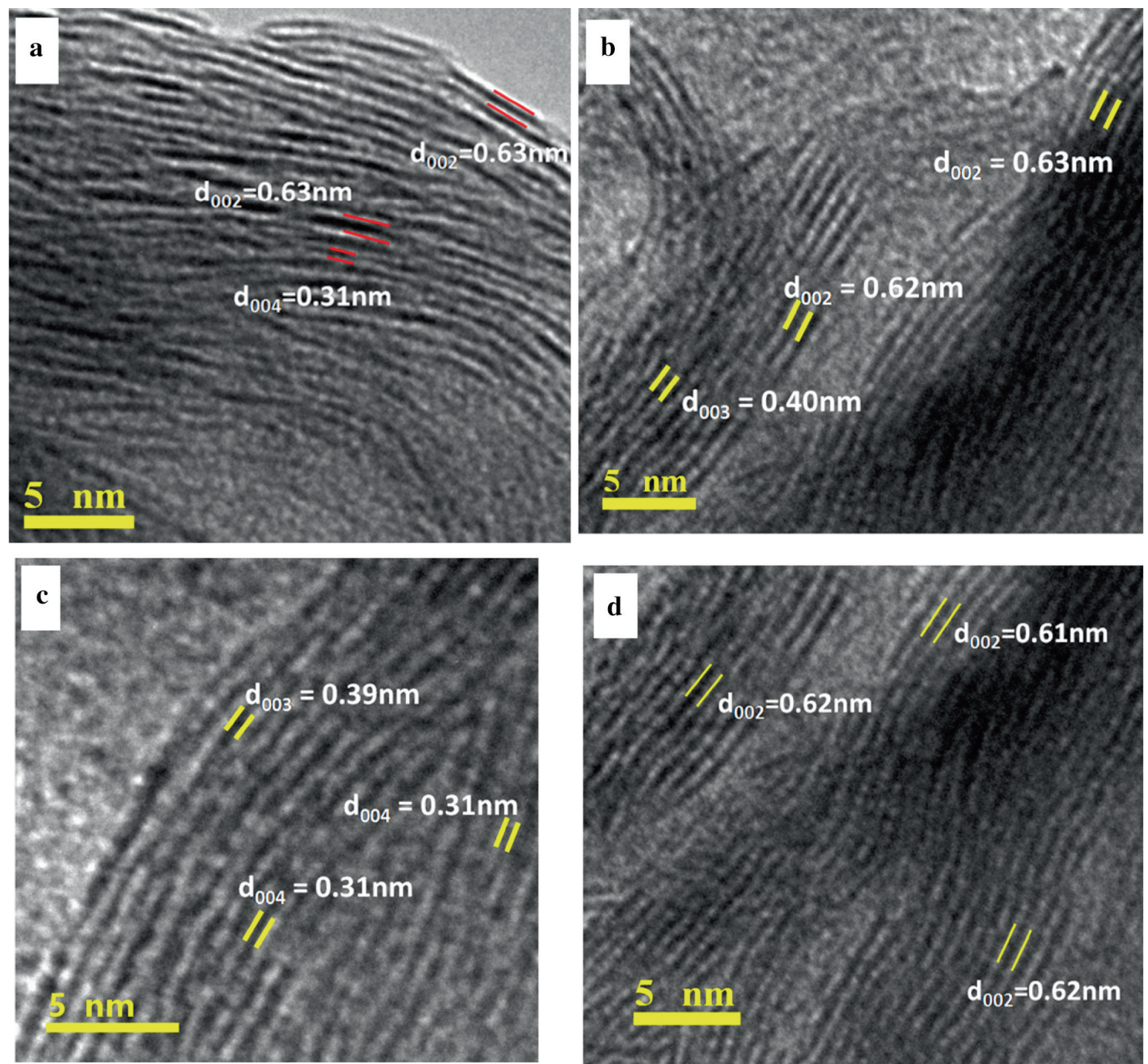

Figure 4. TEM images of (a) $\mathrm{MoS}_{2}$, (b) $\mathrm{WS}_{2}$, (c) MoW-disulphide1 and (d) MoW-disulphide2 showing different Millar planes of the respective materials.

spacing of 0.62 and $0.4 \mathrm{~nm}$ in $\mathrm{WS}_{2}$ as observed in figure $4 \mathrm{~b}$ correspond to Millar planes (002) and (003), respectively. Again, for MoW-disulphide1 interplanar spacing of 0.31 and $0.39 \mathrm{~nm}$ in figure $4 \mathrm{c}$ may be due to (004) and (003) Millar planes, respectively. Also, in figure $4 \mathrm{~d}$ spacing of $0.62 \mathrm{~nm}$ is due to the crystallographic plane (002) in MoW-disulphide2 considering the structure of the ternary compound to be hexagonal, the most stable structure in the case of TMDs.

To investigate the light absorption behaviour, we have also analysed the UV-Vis absorption spectra of the prepared samples. The UV-Vis spectra in figure $2 \mathrm{~b}$ reveal that there is good absorption of light in the visible region and in the UV region $(250-350 \mathrm{~nm})$ for all the as-synthesized materials. More than
Table 3. Optical energy BG calculation using the KM plot.

\begin{tabular}{ll}
\hline Sample & \multicolumn{1}{c}{$E_{\mathrm{g}}(\mathrm{eV})$} \\
\hline $\mathrm{MoS}_{2}$ & $2.76,1.56$ \\
$\mathrm{WS}_{2}$ & $2.74,1.58$ \\
MoW-disulphide1 & $2.84,2.41,1.65$ \\
MoW-disulphide2 & $2.65,1.45$ \\
\hline
\end{tabular}

one edge of the spectra also indicated different dimensions of the material. For $\mathrm{MoS}_{2}$ samples, near 610 and $660 \mathrm{~nm}$ and for the $\mathrm{WS}_{2}$ sample, near 620 and $655 \mathrm{~nm}$ absorption peaks are 
observed which are due to A and B excitonic transitions [30]. The lower energy peak is due to the transition from the upper level of the spin-split valence band (VB) to the conduction band $(\mathrm{CB})$. The higher energy peak for the $\mathrm{B}$ exciton is due to the transition from the lower spin-split level of the VB to the CB near the $k$-valley position of the Brillouin zone (BZ). Another absorption peak occurs around the blue wavelength region due to the $\mathrm{C}$ excitonic transition from the VB to the $\mathrm{CB}$ at a band nesting position between $\Gamma$ and $\Lambda$ positions of the BZ [30-32]. In general, electronic transitions may occur mainly in three different ways namely (a) transition involving $\mathrm{s}, \mathrm{p}$ and $\mathrm{n}$ electrons, (b) transition involving charge transfer and (c) transition involving $\mathrm{d}$ and $\mathrm{f}$ electrons. Mo (d block) and $\mathrm{W}$ (f block) are both transition metals containing unfilled $\mathrm{d}$ orbitals. The transition in $\mathrm{d}-\mathrm{d}$ or $\mathrm{f}-\mathrm{f}$ orbitals corresponds to the UV and visible range of light. The presence of S ligands in $\mathrm{MoS}_{2}$ and $\mathrm{WS}_{2}$ splits the d orbitals of Mo and W which in turn facilitate the electronic transition inside the crystal on exposure to radiation of suitable energy.

To determine the optical BG energy $\left(E_{\mathrm{g}}\right)$ of the assynthesized materials, we used the Kubelka-Munk (KM) plot obtained from the diffused reflectance spectra. The KM plot is similar to the Tauc plot which is obtained from the absorption spectra. The KM function $F(R)$ is obtained using equation (5) [33].

$$
F(R)=(1-R)^{2} / 2 R,
$$

where $R$ is the reflection coefficient. The optical BG energy is determined using equation (6).

$$
\{F(R) E\}=A\left(E-E_{\mathrm{g}}\right)^{1 / m},
$$

where $m=2,2 / 3,1 / 2$ and $1 / 3$ for the direct allowed transition, direct forbidden transition, indirect allowed transition and indirect forbidden transition, respectively, $E=h v$, energy of radiation, $h$ and $v$ representing Planck's constant and frequency of vibration, respectively. $A$ is the proportionality constant. The different KM plots of all the as-synthesized samples are shown in figure $2 \mathrm{c}$. The optical BG $\left(E_{\mathrm{g}}\right)$ energies
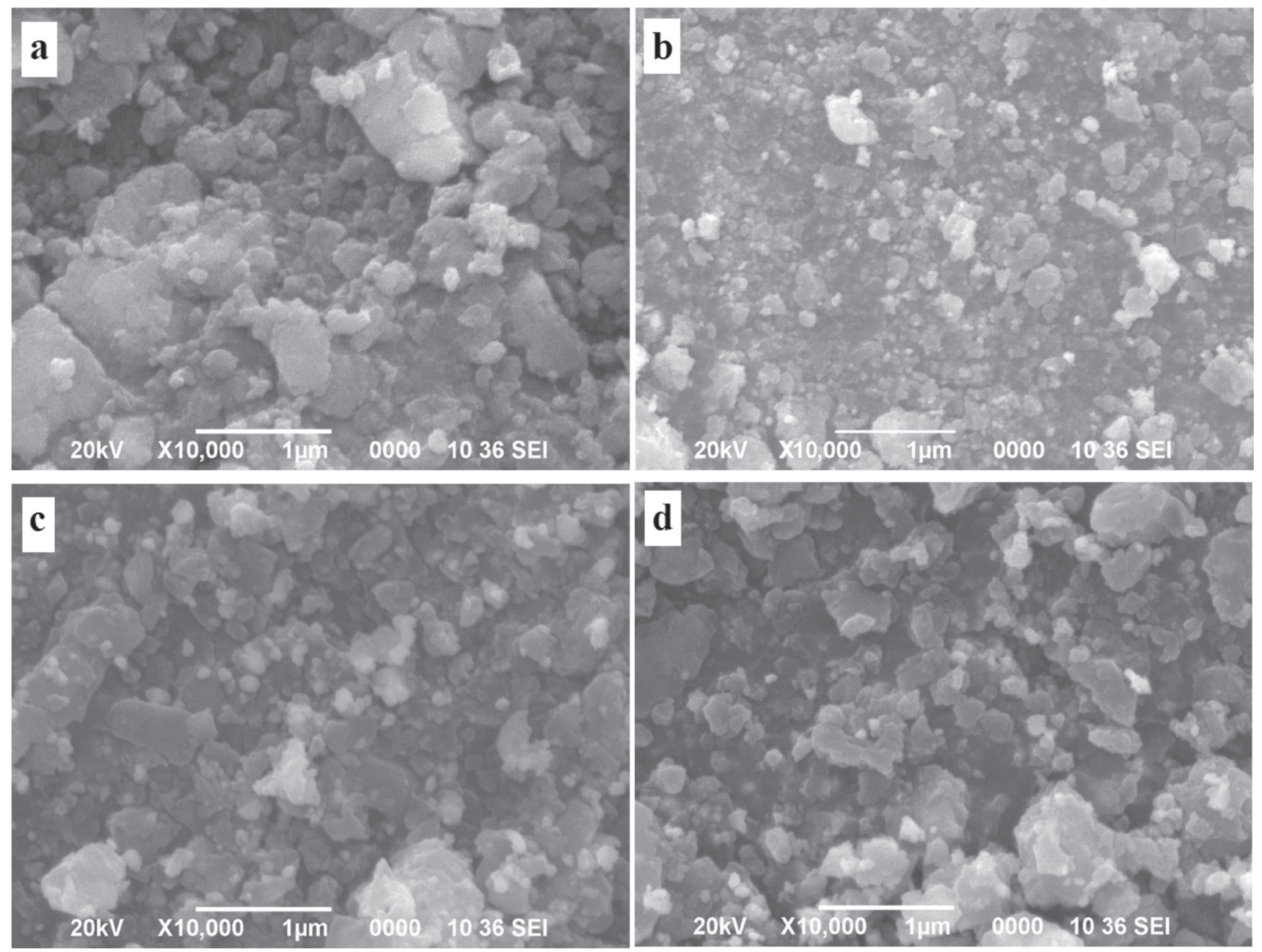

Figure 5. SEM images of (a) $\mathrm{MoS}_{2}$, (b) $\mathrm{WS}_{2}$, (c) MoW-disulphide1 and (d) MoW-disulphide2 NPs. 

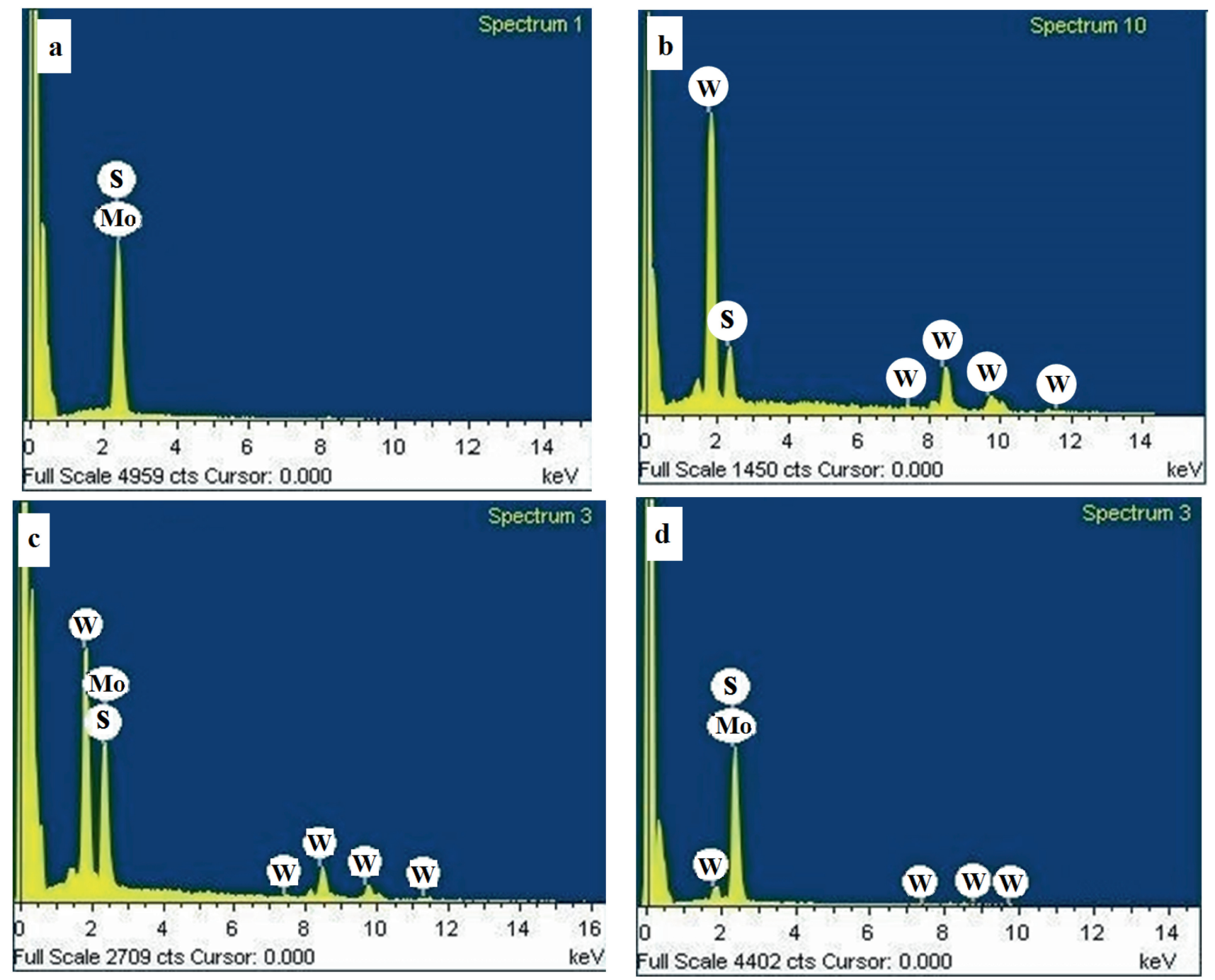

Figure 6. EDX spectra of (a) $\mathrm{MoS}_{2}$, (b) $\mathrm{WS}_{2}$, (c) MoW-disulphide1 and (d) MoW-disulphide2 revealing the presence of main composition elements.

are determined by extrapolating the straight part of the KM plot for all the samples and are shown in table 3.

It has been observed from the KM plot that the transitions for all the samples are multiple and hence lead to multiple $\mathrm{BG}$ materials. High values of BGs are due to the band nesting transitions [30,32]. In $\mathrm{MoS}_{2}, \mathrm{WS}_{2}$ and MoW-disulphide2 NP samples, there are two BG values whereas in MoWdisulphide1 NPs, there are possibly three BG values. The dominance of $\mathrm{W}$ in disulphide1 compound NPs may be the reason behind having an extra BG value compared to the other two samples. From table 3 , it is found that the compound disulphide 1 has the highest BG energy which corresponds to a visible blue light wavelength. The increase in the BG for this sample is due to the insertion of the larger atom $\mathrm{W}$ in the lattice site of $\mathrm{MoS}_{2}$. Actually, the above anomalies in MoWdisulphide1 may be due to the combined effect of ligands $S$ and $\mathrm{W}$ which leads to spin splitted d-orbitals that increase the energy levels and provide an extra energy gap value as well.
The large $\mathrm{BG}$ values are due to the $\mathrm{C}$ excitonic transition at the band nesting position. Also, the high BG energy confirms the nanoscale dimension of the material system [34].

SEM micrographs and EDX spectra of $\mathrm{MoS}_{2}, \mathrm{WS}_{2}, \mathrm{MoW}-$ disulphide1 and MoW-disulphide2 NPs are shown in figure 5. It is observed from SEM micrographs that the size of the particles has different dimensions around 60-100 nm. However, from the micrographs, it seems that the particles get agglomerated. The average particle sizes obtained from SEM images are $62.47\left(\mathrm{MoS}_{2}\right), 50.33\left(\mathrm{WS}_{2}\right), 51.40(\mathrm{MoW}$-disulphide1) and $57.26 \mathrm{~nm}$ (MoW-disulphide2), respectively.

From the EDX spectrographs shown in figure 6, the weight $\%$ and atomic\% of all the samples along with characteristic transition levels are tabulated in tables 4-7. It is found from table 4 that $\mathrm{MoS}_{2}$ is mainly composed of Mo and $\mathrm{S}$, from table 5, we can conclude that $\mathrm{W}$ and $\mathrm{S}$ are the main composition in the $\mathrm{WS}_{2}$ sample, while from tables 6 and 7 , it is observed that in MoW-disulphide1, the main elements 
Table 4. Percentage composition of $\mathrm{MoS}_{2}$ from the EDX spectrum.

\begin{tabular}{lrc}
\hline Element & Weight\% & Atomic\% \\
\hline S K & 43.57 & 69.79 \\
Mo L & 56.43 & 30.21 \\
Total & 100.00 & \\
\hline
\end{tabular}

Table 5. Percentage composition of $\mathrm{WS}_{2}$ from the EDX spectrum.

\begin{tabular}{lrc}
\hline Element & Weight\% & Atomic\% \\
\hline S K & 30.42 & 71.48 \\
W L & 69.58 & 28.52 \\
Total & 100.00 & \\
\hline
\end{tabular}

Table 6. Percentage composition of MoW-disulphide1 from the EDX spectrum.

\begin{tabular}{lrc}
\hline Element & Weight\% & Atomic\% \\
\hline S K & 23.25 & 60.36 \\
Mo L & 11.79 & 10.23 \\
W M & 64.96 & 29.41 \\
Total & 100.00 & \\
\hline
\end{tabular}

Table 7. Percentage composition of MoW-disulphide2 from the EDX spectrum.

\begin{tabular}{lrr}
\hline Element & Weight\% & Atomic\% \\
\hline S K & 63.34 & 86.23 \\
Mo L & 23.31 & 10.60 \\
W M & 13.35 & 3.17 \\
Total & 100.00 & \\
\hline
\end{tabular}

present are $\mathrm{Mo}, \mathrm{W}$ and $\mathrm{S}$ with the Mo:W atomic\% ratio of 1:3 and in MoW-disulphide2, the Mo:W atomic\% ratio is 3:1, S being most abundant in both MoW-disulphide1 and MoWdisulphide2. Also, the presence of the characteristic peaks of $\mathrm{Mo}, \mathrm{W}$ and $\mathrm{S}$ in EDX spectra confirms their existence in the respective materials [35].

Using the advantage of elemental maps or spot chemical analysis using EDS, the abundance of specific elements and chemical composition of the as-synthesized materials are shown in figure 7.

We have also studied the Raman spectra of the assynthesized materials as it is the characteristic tool which provides a fingerprint by which the material can be identified. The Raman spectra of all the as-prepared samples were obtained at an excitation laser wavelength of $488 \mathrm{~nm}$ $(2.54 \mathrm{eV})$ as shown in figure 8. Here, the Raman spectrum is given as plots of the intensity of Raman scattered radiation as a function of its Raman shift (in units of wavenumber, $\mathrm{cm}^{-1}$ ) and each spectrum has a characteristic set of peaks for the particular material.

The characteristic peaks 384.95 and $406.12 \mathrm{~cm}^{-1}$ in the Raman spectra of $\mathrm{MoS}_{2}$ and 348.34 and $420.01 \mathrm{~cm}^{-1}$ of $\mathrm{WS}_{2} \mathrm{NP}$ samples (figure 8a and $\mathrm{b}$ ) reveal the Raman active vibration modes $E_{2 \mathrm{~g}}^{1}$ and $A_{1 \mathrm{~g}}$ [36-38]. Some resonance Raman peaks at $450 \mathrm{~cm}^{-1}(2 \mathrm{LA}(\mathrm{M})), 496 \mathrm{~cm}^{-1}$ (edge phonon), $526 \mathrm{~cm}^{-1}\left(E_{1 \mathrm{~g}}(\mathrm{M})+\mathrm{LA}(\mathrm{M})\right)$ and $597 \mathrm{~cm}^{-1}$ $\left(E_{2 \mathrm{~g}}^{1}(\mathrm{M})+\mathrm{LA}(\mathrm{M})\right)$ are also observed in $\mathrm{MoS}_{2}$ NPs and $593.07 \mathrm{~cm}^{-1}\left(A_{1 \mathrm{~g}}+\mathrm{LA}(\mathrm{M})\right)$ in the $\mathrm{WS}_{2}$ NP sample because of the comparable value of excitation energy with the BG energy of the as-synthesized $\mathrm{MoS}_{2}$ and $\mathrm{WS}_{2}$ NPs [36]. These peaks are also observed in figure $8 \mathrm{~d}$ for the compound disulphide 2 having smaller $\mathrm{W}$ content with a slight shift but different peaks are observed in the Raman spectrum of the compound disulphide1 (figure 8c) having higher W content which affirms the formation of new bonds. Since Raman spectroscopy also detects phonon activity, the phonon lifetime of the samples is also calculated using the energy-time uncertainty equation (7) [29]

$$
\frac{1}{\tau}=\frac{\Delta E}{h}=\frac{\pi c \Gamma}{2}
$$

where $\Delta E$ is the uncertainty in energy, $h$ the Planck's constant, $c$ the speed of light in vacuum and $\Gamma$ the FWHM of the Raman peaks in $\mathrm{cm}^{-1}$. The phonon lifetime obtained from Raman spectra for all the three as-synthesized samples is found to be in the range of picoseconds (tabulated in tables 8-11). The larger phonon lifetime indicates that the samples have larger defect states that may trap the phonon for a longer time. A lower value of the phonon lifetime in MoW-disulphide1 compared to other two samples is due to less number of defects in it and thus, leading to a larger crystallite size.

Being SC, the luminescence properties of the as-synthesized materials are studied. We have investigated whether there is any distinguished behaviour in the luminescence properties of the TMD compound NPs as compared to that of $\mathrm{MoS}_{2}$ and $\mathrm{WS}_{2}$ NPs. We have analysed PL spectra to measure the emission BG of new ternary compound SCs. The PL spectra of the as-synthesized materials are shown in figure 9. In PL characterization, the excitation wavelength chosen is in the UV $(300 \mathrm{~nm})$ region in figure 9a and in the visible $(500 \mathrm{~nm})$ region in figure $9 \mathrm{~b}$.

Analysing the PL spectra in figure 9, it has been observed that there is an enhancement in the luminescence of the compound disulphide having a higher W:Mo ratio. The luminescence peaks are observed at $\sim 659 \mathrm{~nm}(1.88 \mathrm{eV})$ for excitation wavelength of $500 \mathrm{~nm}$ and at $\sim 462 \mathrm{~nm}(2.68 \mathrm{eV})$ for excitation wavelength of $300 \mathrm{~nm}$. The PL near $659 \mathrm{~nm}$, 


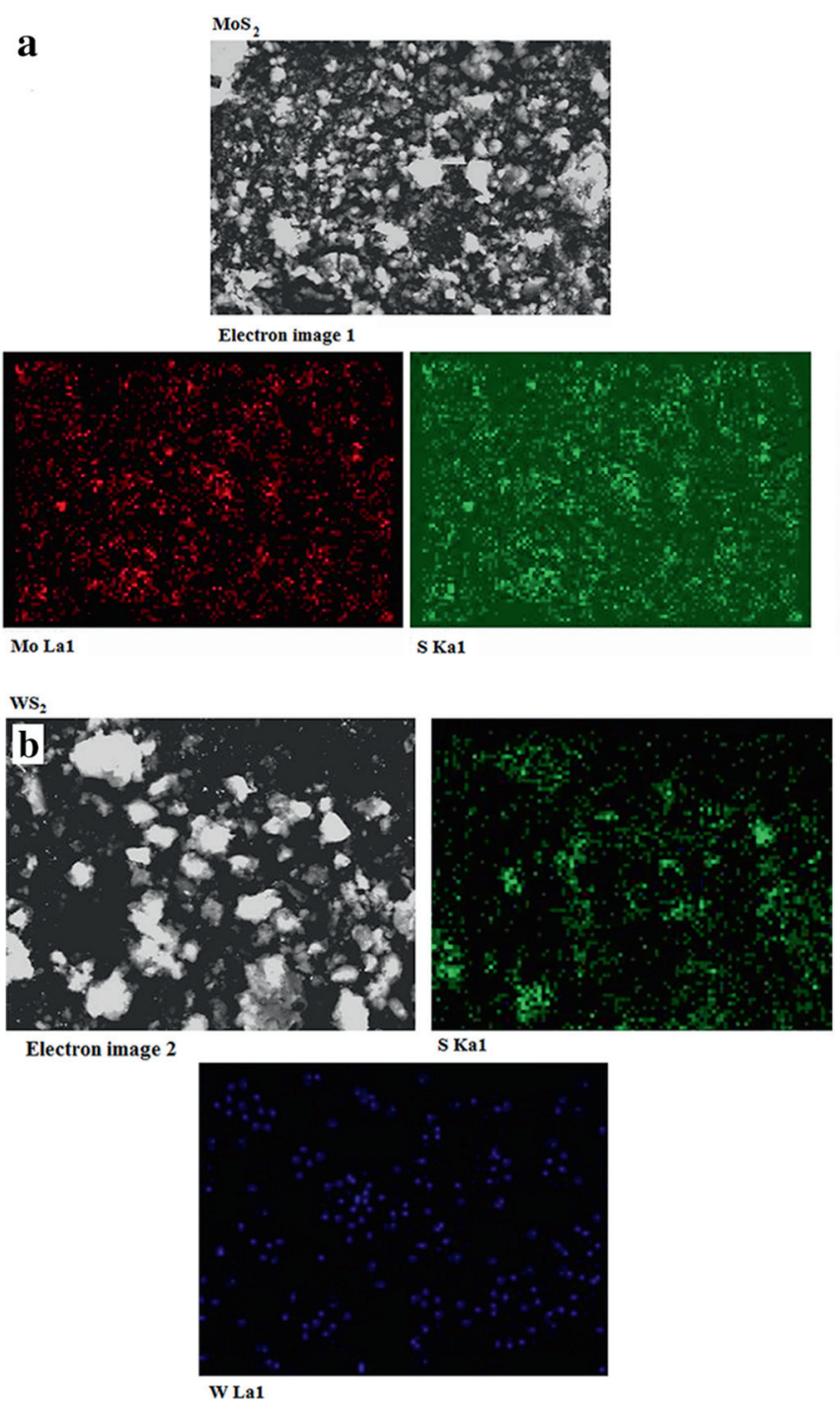

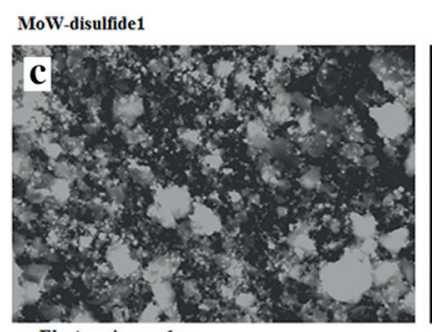

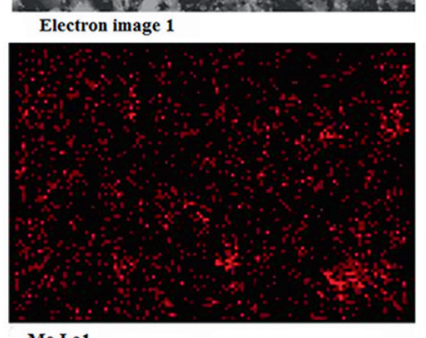

Mo La1

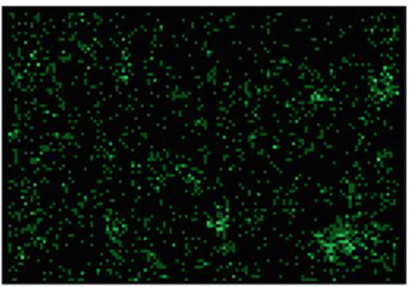

S Ka1

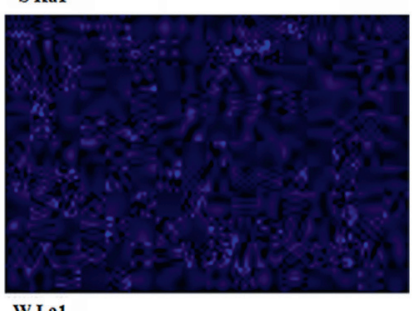

W La1

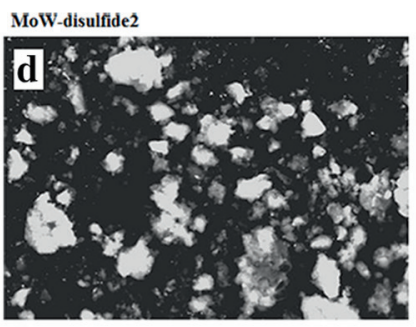

Electron image 1

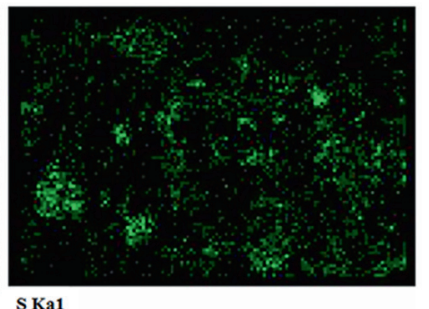

S Ka1

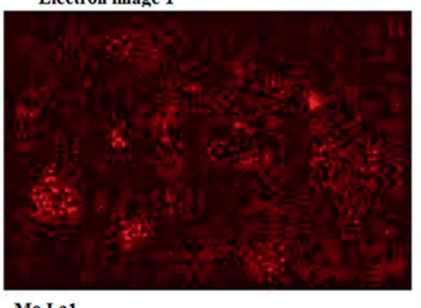

Mo La1

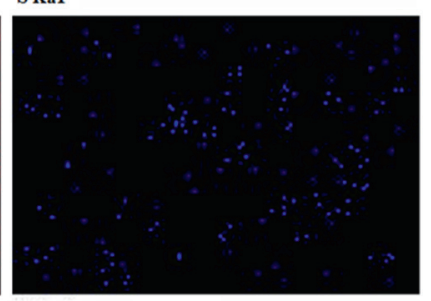

W La1

Figure 7. EDX elemental mapping of (a) $\mathrm{MoS}_{2}$, (b) $\mathrm{WS}_{2}$, (c) MoW-disulphide1 and (d) MoW-disulphide2 (the green, red and blue dots represent $\mathrm{S}$, Mo and $\mathrm{W}$ elements, respectively, present in the samples).

for exciton energy of $1.88 \mathrm{eV}$, is observed due to the $\mathrm{B}$ excitonic transition, while for exciton energy of $2.68 \mathrm{eV}$, PL near $462 \mathrm{~nm}$ is observed for the $\mathrm{C}$ excitonic transition. The near BG emission in the PL spectra reveals the direct BG nature of the as-synthesized sulphides. In the case of MoW-disulphide1 NPs, the PL peak is enhanced by about two times from that of $\mathrm{MoS}_{2}$ NPs and 1.7 times than that of $\mathrm{WS}_{2}$ NPs. It is observed that $\mathrm{WS}_{2}$ NPs have slightly higher PL intensity than that of $\mathrm{MoS}_{2}$ NPs. This may be due to the effect of larger $\mathrm{W}$ atom which provides more exciton pairs in $\mathrm{WS}_{2}$ NPs as compared to Mo in $\mathrm{MoS}_{2}$ NPs. The compound disulphides of $\mathrm{W}$ and Mo combination having higher $\mathrm{W}$ content give rise to increase in luminescence. Higher W content in the ternary sulphide enhances the PL intensity. This is probably due to the increase in the number of photo-excitons with the insertion of $\mathrm{W}$ in higher amounts and a higher density of generated photo-excitons increases the PL intensity by the process of radiative recombination. It can also be due to the presence of less number of defects in the ternary disulphide 1 compound as it has the highest value of crystallite size [39]. Also, DFT investigation in the preceding section 3.2 reveals that W insertion in the $\mathrm{MoS}_{2}$ system leads the system towards a direct BG SC which, in turn, leads to enhanced PL emission as observed in our experiment.

\subsection{Theoretical investigation of effect of $W$ doping in the $\mathrm{MoS}_{2}$ lattice structure by using DFT}

We have investigated the changes brought out by the addition of W in the $\mathrm{MoS}_{2}$ system. We optimized three systems: (i) $\left(\mathrm{MoS}_{2}\right)_{8}$ or $\mathrm{Mo}_{8} \mathrm{~S}_{16}$, (ii) $\mathrm{Mo}_{8} \mathrm{WS}_{16}$ and (iii) $\left(\mathrm{MoWS}_{2}\right)_{8}$ or $\mathrm{Mo}_{8} \mathrm{~W}_{8} \mathrm{~S}_{16}$. The clone models are shown in figure $10 \mathrm{a}, \mathrm{b}$ and c, respectively. 

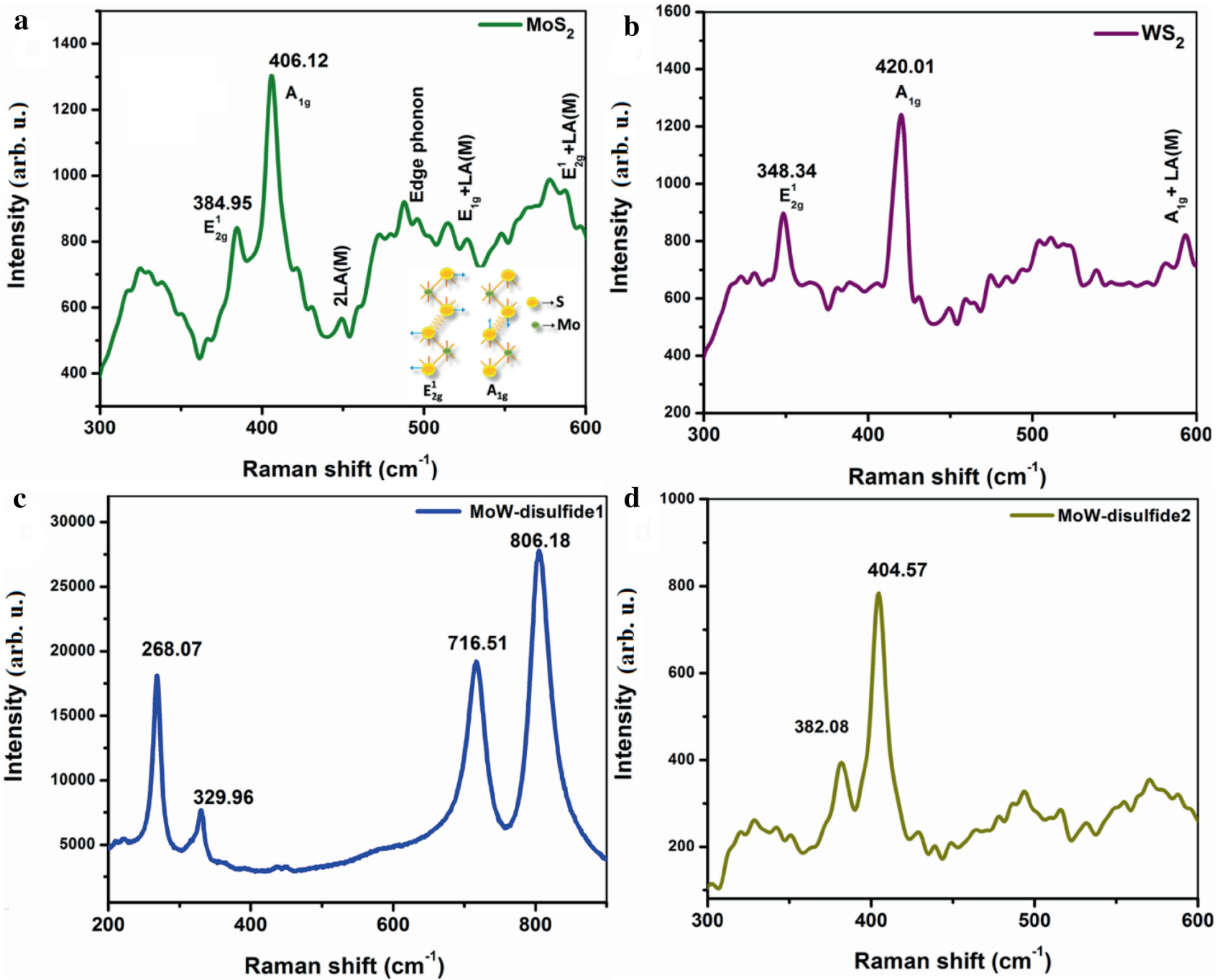

Figure 8. Raman spectra of (a) $\mathrm{MoS}_{2}$ (inset $E_{2 \mathrm{~g}}^{1}$ and $A_{1 \mathrm{~g}}$ active modes), (b) WS 2 , (c) MoW-disulphide1 and (d) MoW-disulphide2 NPs.

Table 8. Determination of the phonon lifetime in the $\mathrm{MoS}_{2}$ sample from Raman spectra.

\begin{tabular}{lc}
\hline Peak $\left(\mathrm{cm}^{-1}\right)$ & Phonon lifetime $(\mathrm{ps})$ \\
\hline 384.95 & 3.39 \\
406.15 & 2.78 \\
\hline
\end{tabular}

Table 9. Determination of the phonon lifetime in the $\mathrm{WS}_{2} \mathrm{NP}$ sample from Raman spectra.

\begin{tabular}{lc}
\hline Peak position $\left(\mathrm{cm}^{-1}\right)$ & Phonon lifetime (ps) \\
\hline 348.34 & 1.67 \\
420.01 & 1.96 \\
\hline
\end{tabular}

Table 10. Determination of the phonon lifetime in the MoW-disulphide1 sample from Raman spectra.

Peak $\left(\mathrm{cm}^{-1}\right)$

Phonon lifetime (ps)

$268.07 \quad 1.84$

$329.96-2.39$

$716.51-0.83$

\begin{tabular}{lr}
716.51 & 0.83 \\
\hline
\end{tabular}

Table 11. Determination of the phonon lifetime in the MoW-disulphide2 sample from Raman spectra.

Peak $\left(\mathrm{cm}^{-1}\right)$ Phonon lifetime (ps)

382.08 2.494

404.57

2.34 

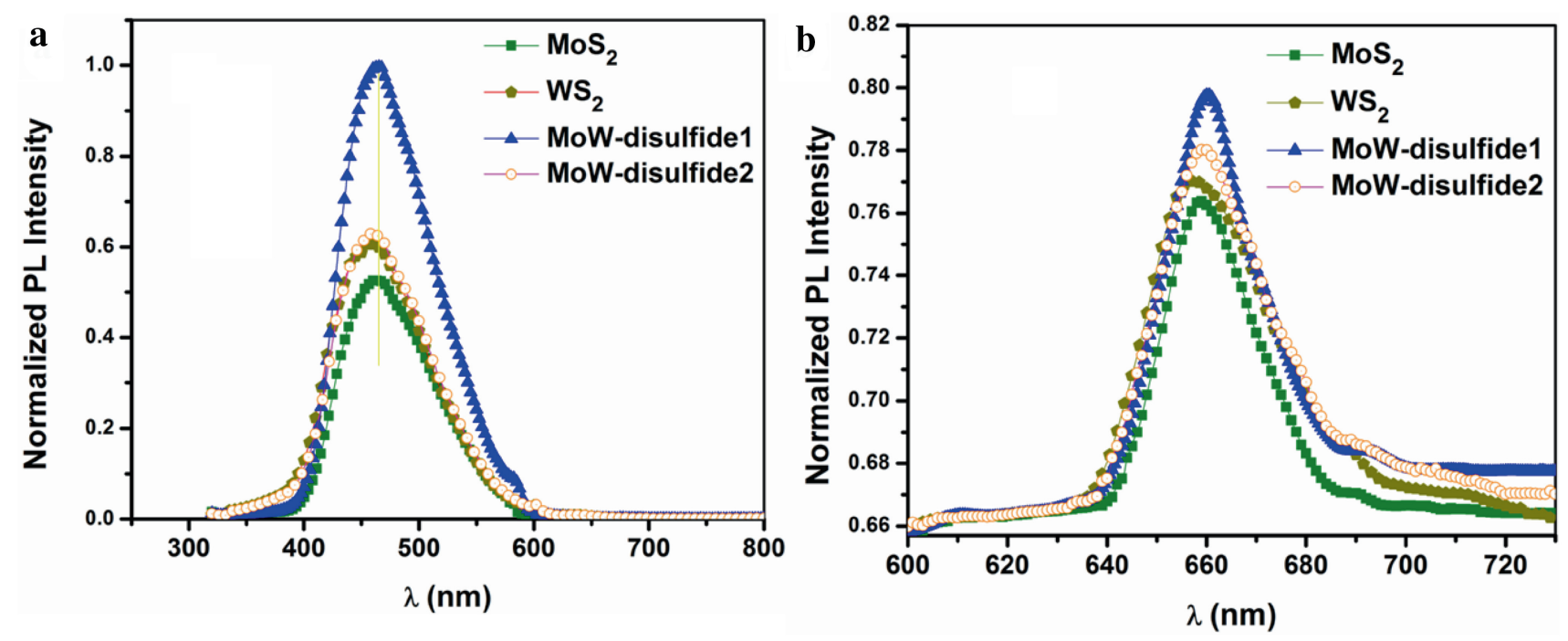

Figure 9. PL spectra of $\mathrm{MoS}_{2}, \mathrm{WS}_{2}, \mathrm{MoW}$-disulphide 1 and MoW-disulphide2 NPs at (a) $300(4.133 \mathrm{eV})$ and (b) $500 \mathrm{~nm}(2.48 \mathrm{eV})$. The enhancement of the PL peak is observed in the case of disulphide1 compound which has the largest and twice the normalized intensity than that of $\mathrm{MoS}_{2}$ NPs and 1.7 times than that of $\mathrm{WS}_{2}$ NPs.
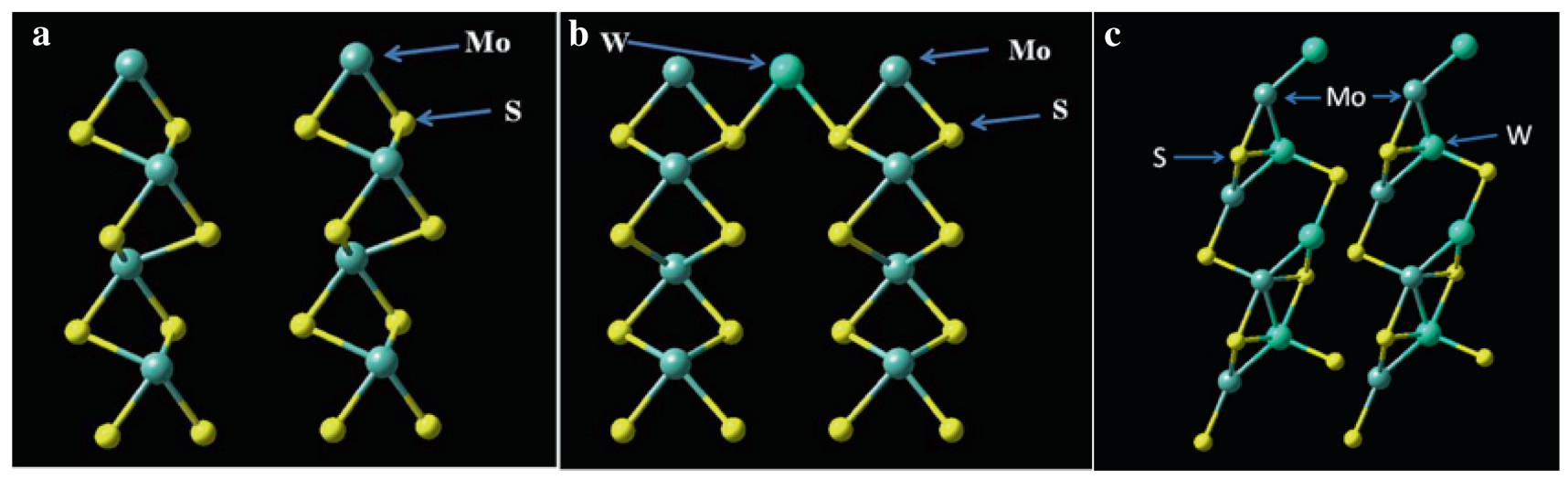

Figure 10. DFT model of (a) $\mathrm{Mo}_{8} \mathrm{~S}_{16}$, (b) $\mathrm{Mo}_{8} \mathrm{WS}_{16}$ and (c) $\mathrm{Mo}_{8} \mathrm{~W}_{8} \mathrm{~S}_{16}$ systems.

Table 12. Cell parameters of minimized $\mathrm{Mo}_{8} \mathrm{~S}_{16}, \mathrm{Mo}_{8} \mathrm{WS}_{16}$ and $\mathrm{Mo}_{8} \mathrm{~W}_{8} \mathrm{~S}_{16}$ systems.

\begin{tabular}{lrrr}
\hline Cell parameters & $\mathrm{Mog}_{8} \mathrm{~S}_{16}$ & $\mathrm{Mo}_{8} \mathrm{WS}_{16}$ & $\mathrm{Mo}_{8} \mathrm{~W}_{8} \mathrm{~S}_{16}$ \\
\hline$a$ & 14.828996 & 13.591858 & 14.652129 \\
$b$ & 11.023554 & 11.078050 & 14.342715 \\
$c$ & 6.364098 & 6.396561 & 8.728053 \\
Alpha & 149.999733 & 150.004255 & 156.728332 \\
Beta & 89.917164 & 90.034854 & 88.954058 \\
Gamma & 90.443033 & 90.079907 & 88.755801 \\
Cell volume, $\AA^{3} 520.123932$ & 481.503624 & 721.114032 \\
\hline
\end{tabular}

Incorporation of $\mathrm{W}$ into $\mathrm{Mo}_{8} \mathrm{~S}_{16}$ i.e., $\mathrm{Mo}_{8} \mathrm{WS}_{16}$ leads to a more stable structure than $\mathrm{Mo}_{8} \mathrm{~S}_{16}$ whereas $\mathrm{Mo}_{8} \mathrm{~W}_{8} \mathrm{~S}_{16}$ is the most stable structure. The volume of the cell (table 12) $\mathrm{Mo}_{8} \mathrm{~S}_{16}$ gets compressed by adding $\mathrm{W}$ to it in $\mathrm{Mo}_{8} \mathrm{WS}_{16}$, but $\mathrm{Mo}_{8} \mathrm{~W}_{8} \mathrm{~S}_{16}$ has the largest volume. This is because when the
$\mathrm{W}$ atom is not introduced, spacing between the nearby layers of $\mathrm{MoS}_{2}$ remains available which is called interlayer spacing. As a result of addition of $\mathrm{W}$ atom in the $\mathrm{Mo}_{8} \mathrm{WS}_{16}$ structure, new bonds are formed among the $\mathrm{MoS}_{2}$ layers and $\mathrm{W}$ atom which make the layers closer and the structure become compact. But when the number of $\mathrm{W}$ atoms becomes more or equal to that of Mo atoms in the model compound $\mathrm{Mo}_{8} \mathrm{~W}_{8} \mathrm{~S}_{16}, \mathrm{~W}$ forms new bonds in the layers and become part of it. Together with the interlayer spacing, the larger size of $\mathrm{W}$ atoms, which requires more space, also results in the expansion of the system. The different cell parameters of the minimized structures are included in table 12 .

The electronic band structures of all the above mentioned models are investigated. It is found that the systems $\mathrm{Mo}_{8} \mathrm{~S}_{16}$ and $\mathrm{WMo}_{8} \mathrm{~S}_{16}$ are the indirect $\mathrm{BG}$ system, whereas $\mathrm{W}_{8} \mathrm{Mo}_{8} \mathrm{~S}_{16}$ has become a direct $\mathrm{BG}$ system as shown in figure $11 \mathrm{a}-\mathrm{c}$. We have observed that in the model $\mathrm{Mo}_{8} \mathrm{~W}_{16}$, the CB minimum is not located at the same $K$ value of the VB maximum. This type of band profile is also observed in the 
a Electronic Band Structure for (Mo S2)8 (P1) 326 minimized (job 340)
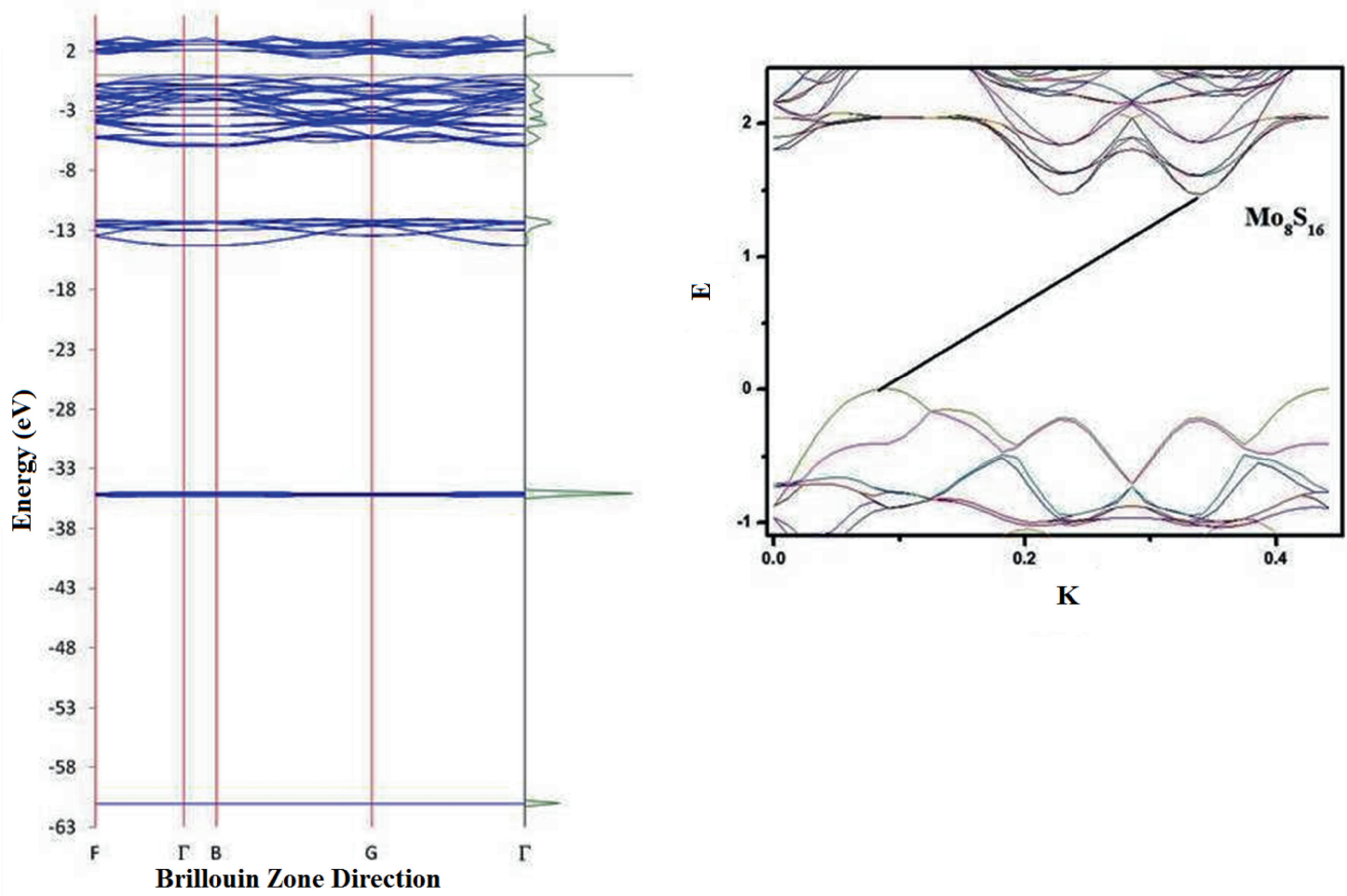

b Electronic Band Structure for W Mo8 S16 (P1) 329 minimized (job 342)
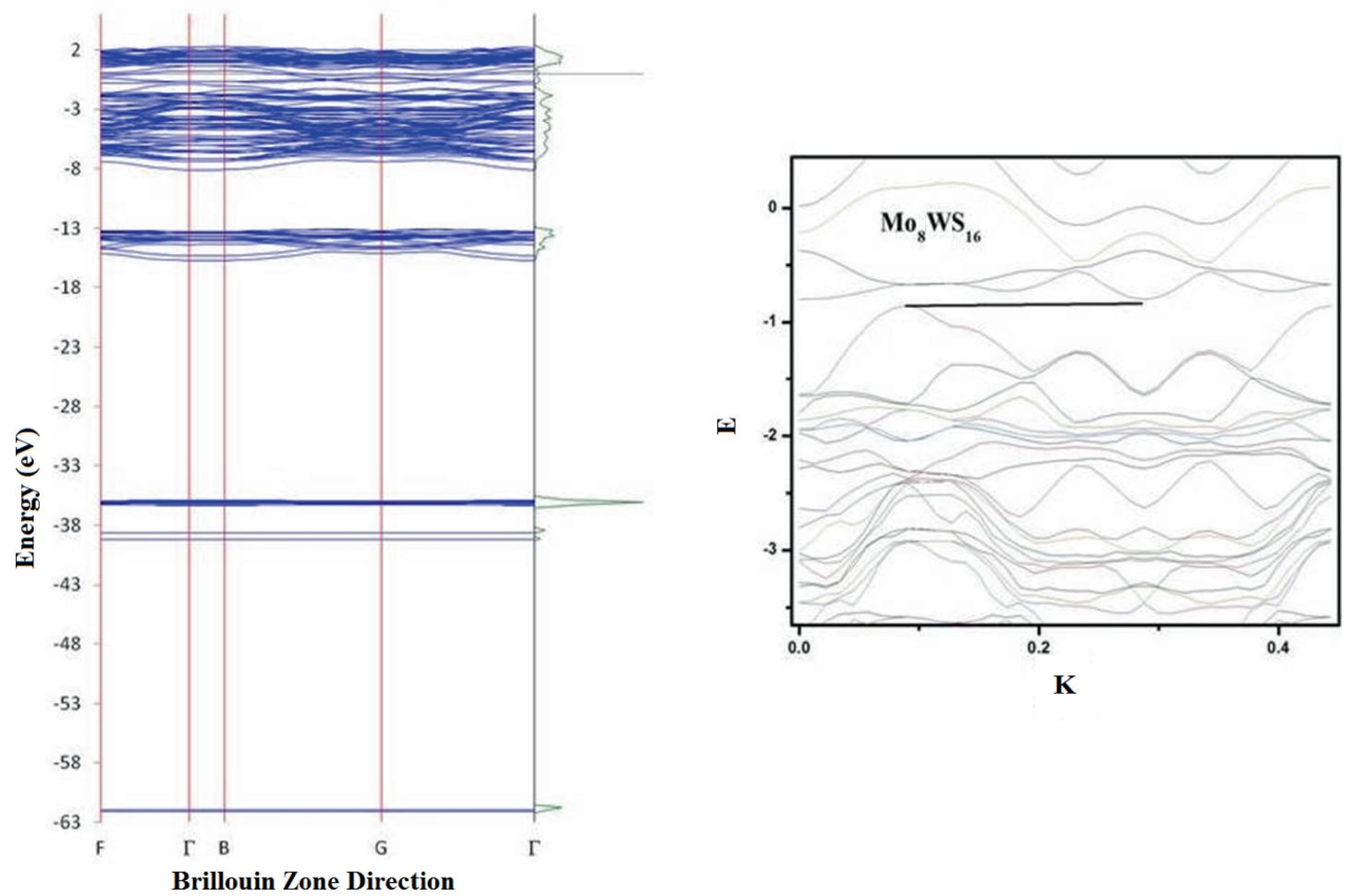

Figure 11. Band structure plot of (a) $\mathrm{Mo}_{8} \mathrm{~S}_{16}$, (b) $\mathrm{Mo}_{8} \mathrm{WS}_{16}$ and (c) $\mathrm{Mo}_{8} \mathrm{~W}_{8} \mathrm{~S}_{16}$. The inset in each plot shows that the system transits from indirect to direct BG system. 
c Electronic Band Structure for (W Mo S2)8 (P1) 341 initial (job 345)

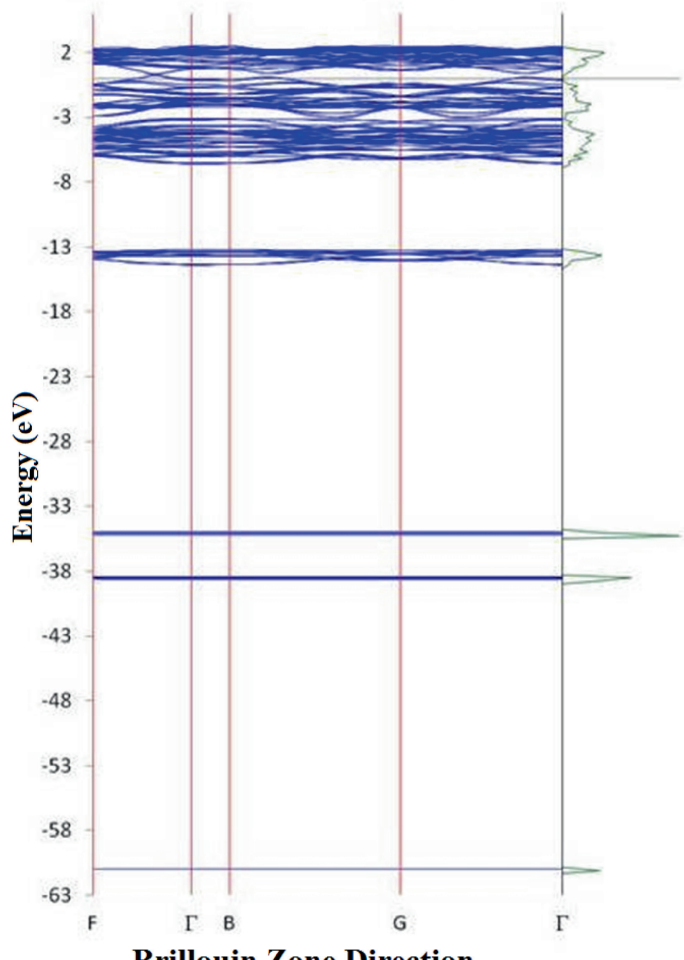

Brillouin Zone Direction

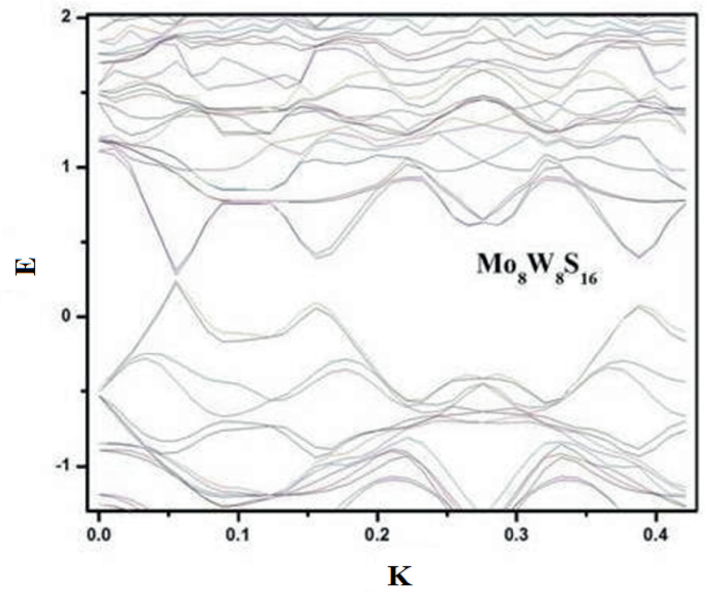

$\mathbf{K}$

Figure 11. continued

case of the $\mathrm{Mo}_{8} \mathrm{WS}_{16}$ system. But in the case of the $\mathrm{Mo}_{8} \mathrm{~W}_{8} \mathrm{~S}_{16}$ system, it is clearly seen that the VB maximum and CB minimum reside on the same $K$ point, which depicts its direct BG nature. The BG calculation error in DFT calculation is an obvious matter, but from band structure calculation, we can map some idea about the variation in the electronic band structure of the above mentioned systems.

We have also investigated TDOS and PDOS of all the three systems. The TDOS plot of all the system is shown in figure 12. The Fermi level is considered at $0 \mathrm{eV}$, since we are more concerned about the states which are nearby the Fermi level. These are the states which actively take part in optical transitions. The TDOS plot (black plot in figure 12) of the $\mathrm{Mo}_{8} \mathrm{~S}_{16}$ system shows a finite BG. The TDOS plot (red plot in figure 12) shows that the $\mathrm{Mo}_{8} \mathrm{WS}_{16}$ system has continuous states i.e., it can be considered as a semi metallic system. Also, the TDOS plot (blue plot in figure 12) of $\mathrm{Mo}_{8} \mathrm{~W}_{8} \mathrm{~S}_{16}$ shows a finite, but small BG which reveals the semiconducting nature of the system. Since the BG calculation of DFT is always less than the experimental value, so these states can be considered as the generation of sub-states within the BG of the system.

The PDOS for different states of Mo and $\mathrm{S}$ for the $\mathrm{Mo}_{8} \mathrm{~S}_{16}$ system is shown in figure 13a and $b$. The PDOS of $\mathrm{S}$ shows $s$ and $p$ states and the s states hardly contribute in the nearby region of the Fermi level, whereas the existence of $p$

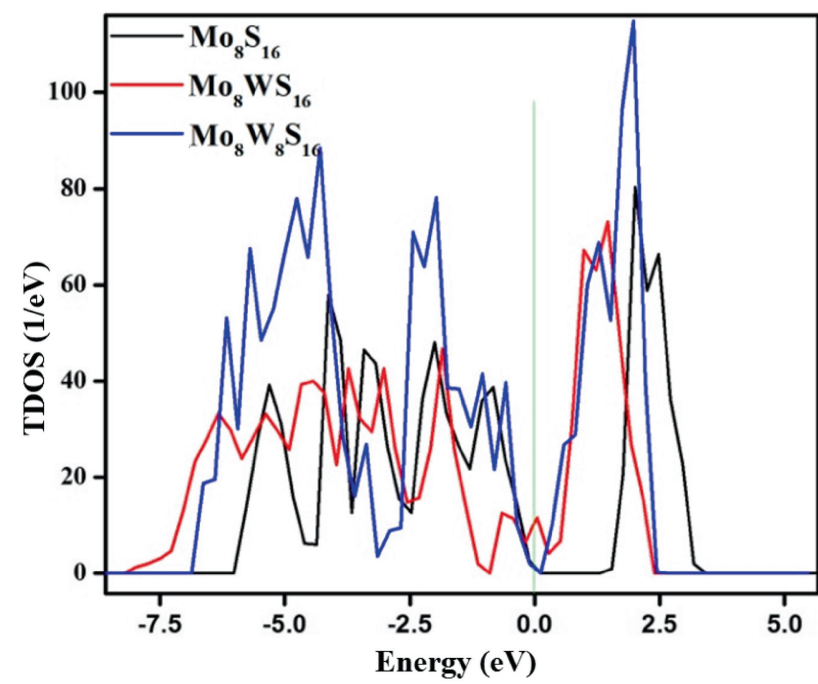

Figure 12. TDOS plot of $\mathrm{Mo}_{8} \mathrm{~S}_{16}, \mathrm{Mo}_{8} \mathrm{WS}_{16}$ and $\mathrm{Mo}_{8} \mathrm{~W}_{8} \mathrm{~S}_{16}$.

states nearby the Fermi level is appreciable. In the case of Mo, the contribution of d states near the Fermi level is more dominant than those of $s$ and $p$ states in band formation which is obvious because Mo is a d-block element. 

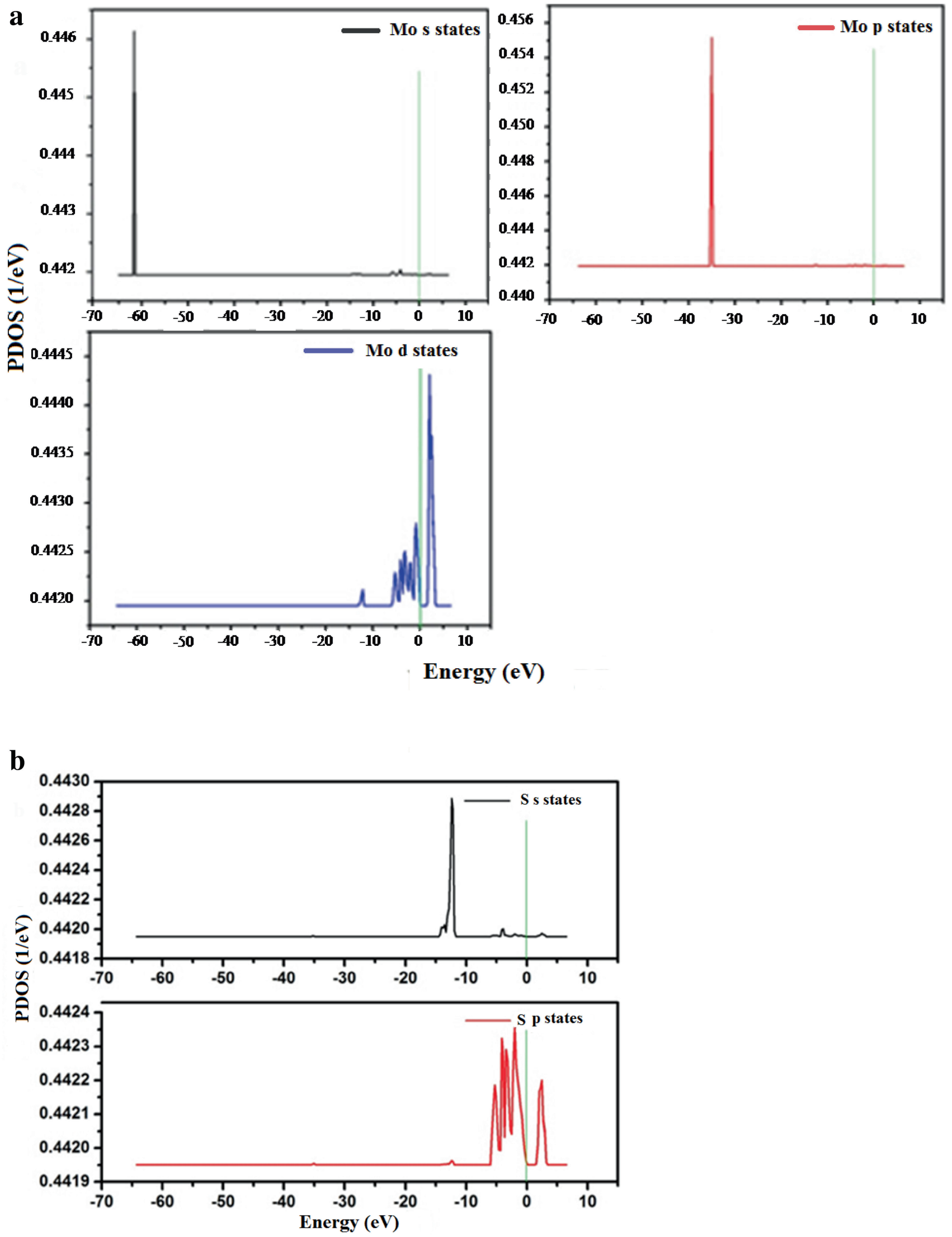

Figure 13. PDOS plot of $\mathrm{Mog}_{8} \mathrm{~S}_{16}$ : (a) various states of Mo and (b) states of $\mathrm{S}$. 

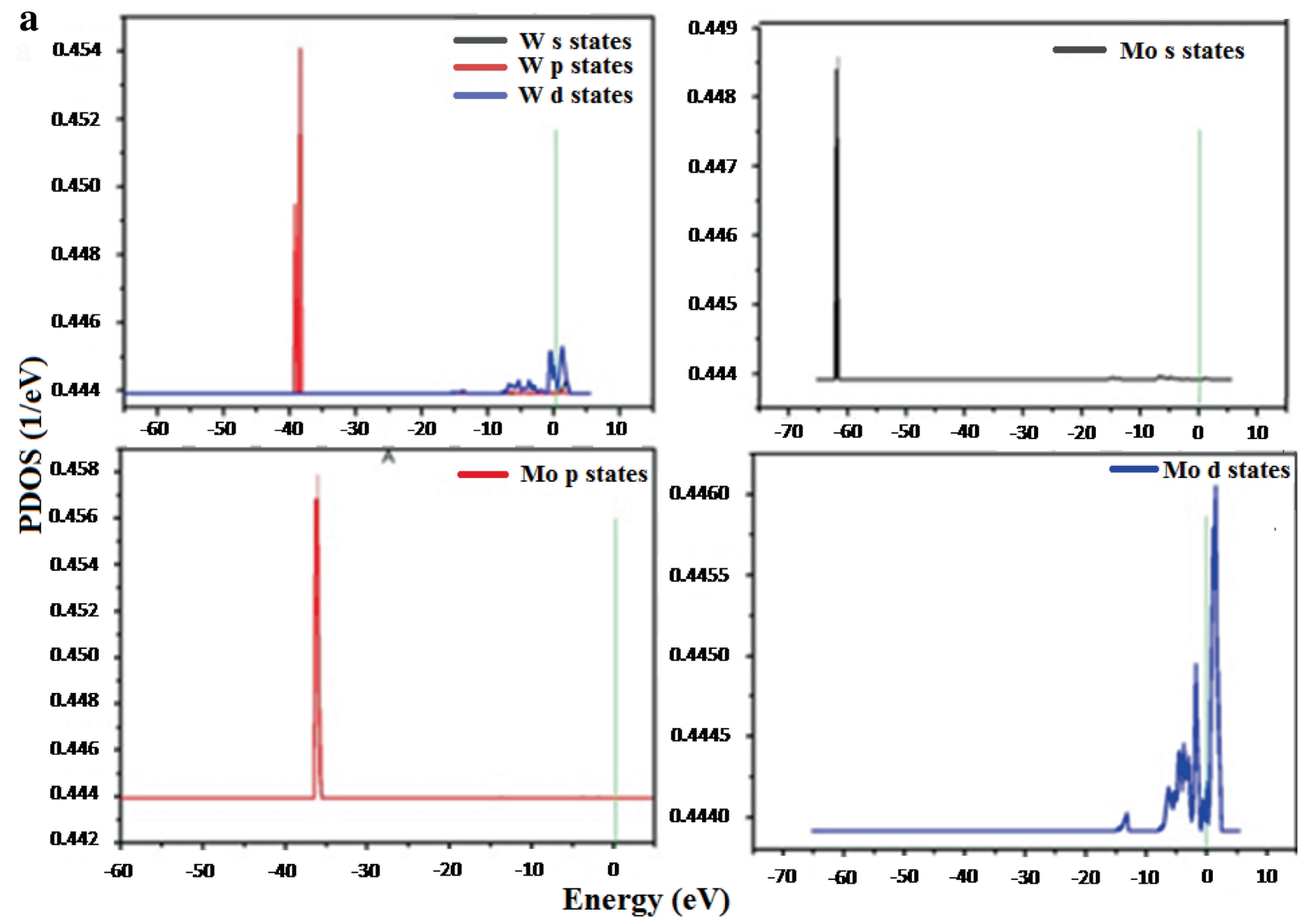

b

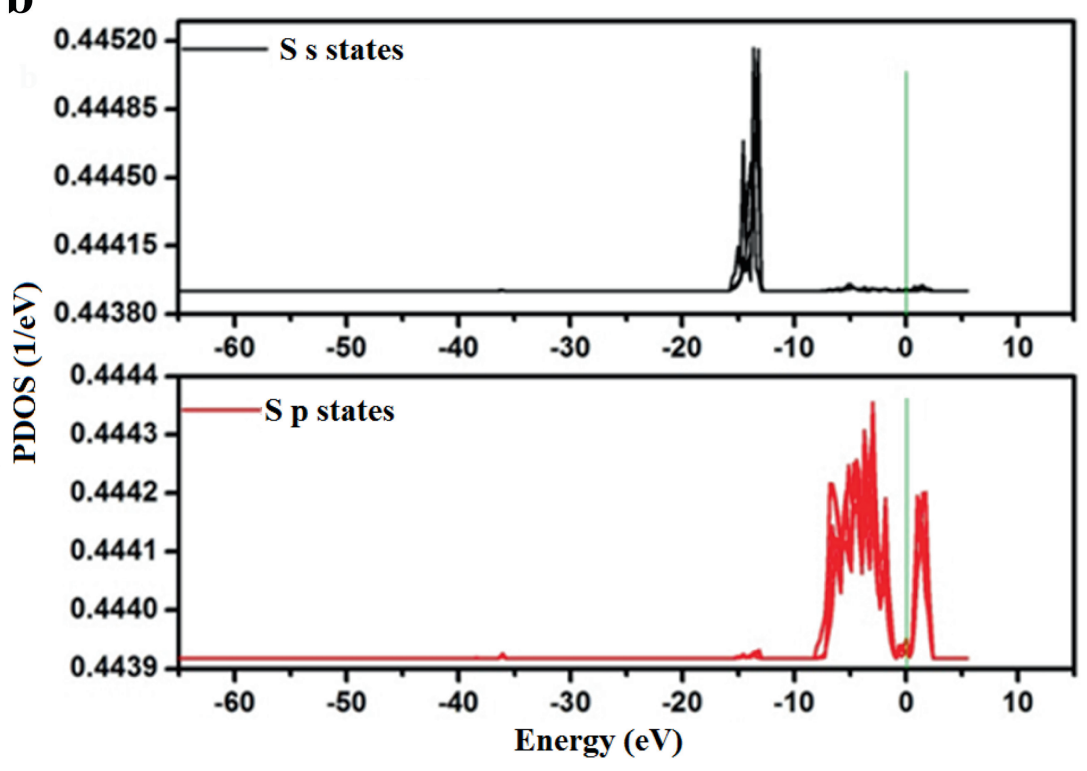

Figure 14. PDOS plot of $\mathrm{Mo}_{8} \mathrm{WS}_{16}$ : (a) various states of $\mathrm{Mo}$ and $\mathrm{W}$ and (b) states of $\mathrm{S}$.

The PDOS of different states of Mo, W and S of the $\mathrm{Mo}_{8} \mathrm{WS}_{16}$ system is shown in figure $14 \mathrm{a}$ and $\mathrm{b}$. The addition of $\mathrm{W}$ changes the scenario of Mo's $\mathrm{d}$ states nearby the Fermi level; in fact these changes in Mo's d states turn this system into a semi-metallic system. 
$\mathbf{a}$

$\mathbf{a}$
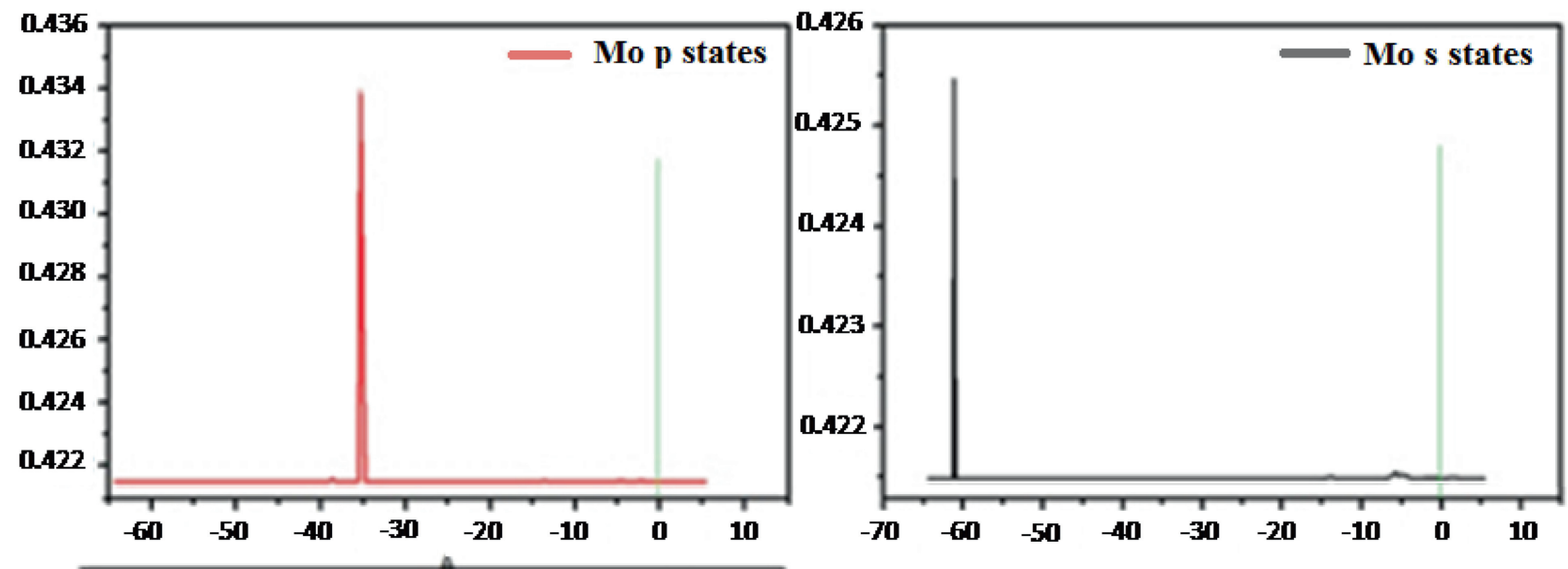

$\frac{8}{2}$

ช

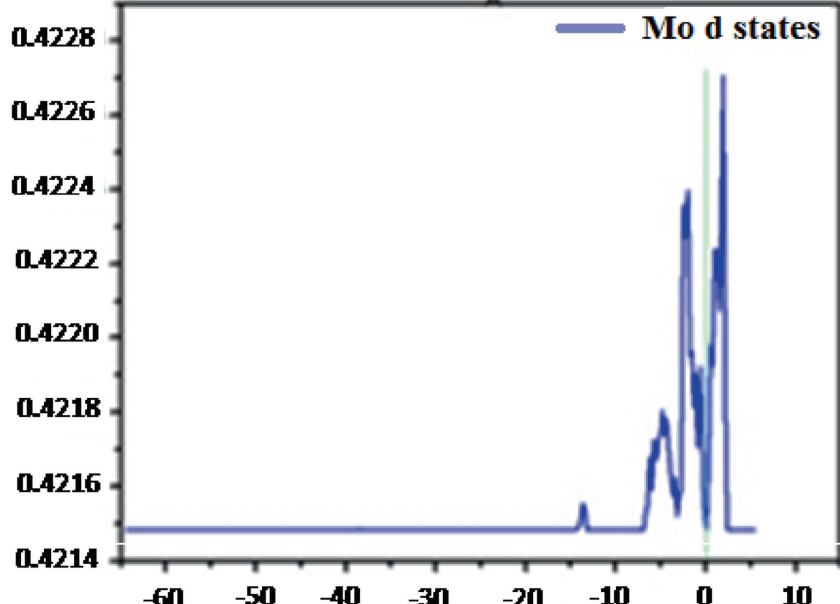

\section{Energy (eV)}

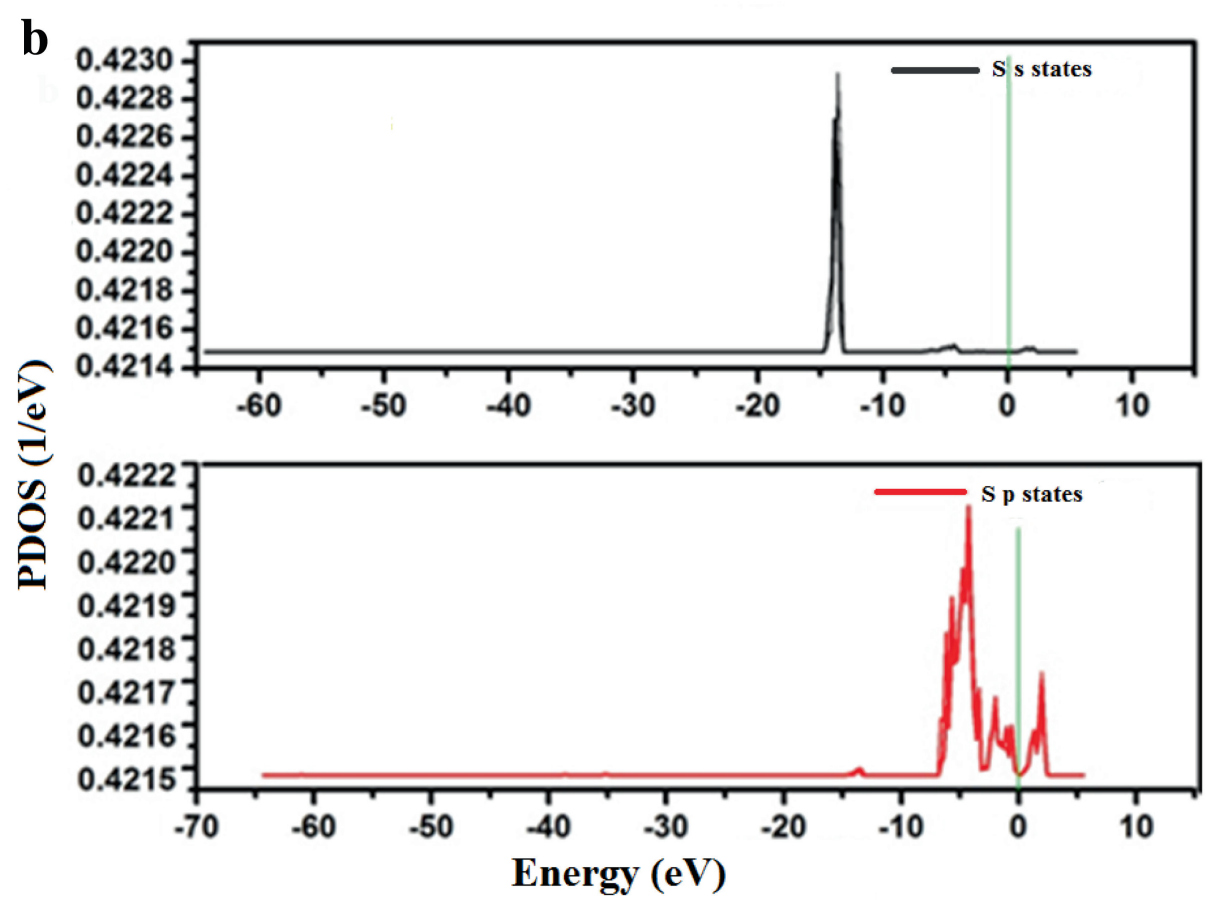

Figure 15. PDOS plot of $\mathrm{Mo}_{8} \mathrm{~W}_{8} \mathrm{~S}_{16}$ : (a) various states of $\mathrm{W}$, (b) states of $\mathrm{S}$ and (c) various states of Mo. 


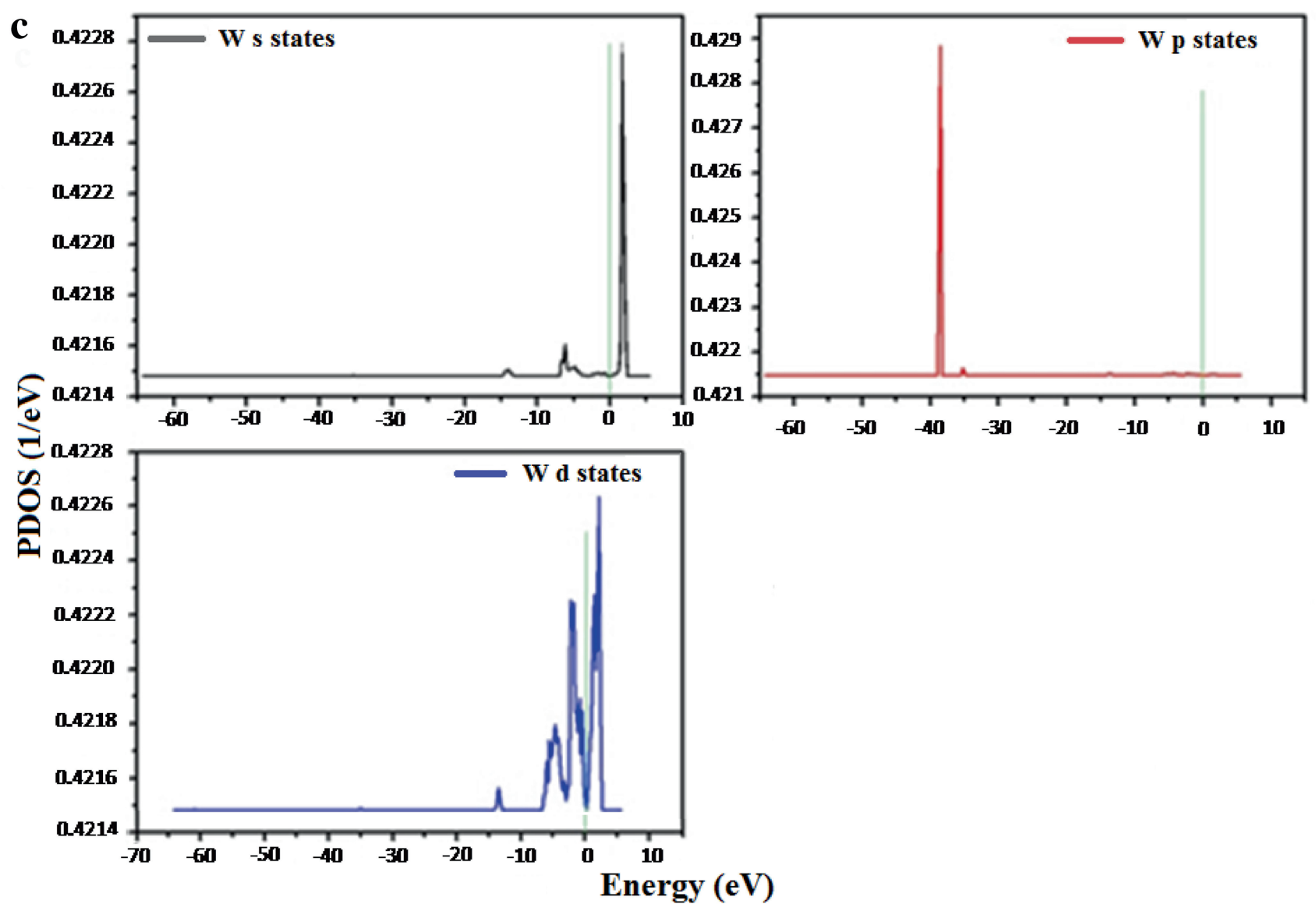

Figure 15. continued

The PDOS of various states of Mo, W and $\mathrm{S}$ of $\mathrm{Mo}_{8} \mathrm{~W}_{8} \mathrm{~S}_{16}$ is shown in figure $15 \mathrm{a}-\mathrm{c}$. The idea to consider this system was to investigate the effects when both $\mathrm{W}$ and Mo are in equal ratio. The PDOS pattern of Mo has changed drastically compared to the last system and the number of states nearby the Fermi level has decreased. This signifies that bonding in this system is much stable and the overall system is much more stable which is in well-agreement with the experimental observation.

\section{Conclusion}

In this paper, we have reported the optical emission properties and chemical composition of the as-synthesized SC ternary TMD compound NPs along with a theoretical investigation of the effect of $\mathrm{W}$ in the $\mathrm{MoS}_{2}$ system. XRD, SEM, EDX and Raman spectral analyses reveal the formation of desired materials having nanoscale size distributions. It has been observed from UV-Vis and PL spectra that the combining effect of $\mathrm{W}$ and Mo in their ternary disulphide compound systems gives rise to different optical properties. The DFT study concluded that the insertion of $\mathrm{W}$ into the $\mathrm{MoS}_{2}$ system makes the ternary compound systems more stable and leads the system towards a direct BG SC when $\mathrm{W}$ and Mo are equal in content which agrees with the experimental results. Enhanced blue PL emission near $463 \mathrm{~nm}$ of the compound MoWdisulphide1 indicated the material's good applicability in luminescence devices. Also, multiple BGs of the ternary compound NPs promise to be a good material for photocatalytic activity.

\section{Acknowledgements}

We are thankful to the Sophisticated Analytical Instrumentation Centre (SAIC), Tezpur University for helping us in providing $\mathrm{N}_{2}$ gas. The second author likes to acknowledge project no. F.5-134/2015-16(MRP/NERO)/51H for the financial support.

\section{References}

[1] Mak K F, Lee C, Hone J, Shan J and Heinz T F 2010 Phys. Rev. Lett. 105136805 
[2] Bernardi M, Palummo M and Grossman J C 2013 Nano Lett. 133664

[3] Elias A L, Perea-Lopez N, Castro-Beltran A, Berkdemir A, Lv R, Feng S et al 2013 ACS Nano 75235

[4] Bernardi M, Ataca C and Grossman M J C 2016 Nanophotonics $\mathbf{5} 111$

[5] Jin W, Yeh P-C, Zaki N, Zhang D, Sadowski J T, Al-Mahboob A et al 2013 Phys. Rev. Lett. 111106801

[6] Butler S Z, Hollen S M, Cao L, Cui Y, Gupta J A, Gutierrez H R et al 2013 ACS Nano 72898

[7] Kuc A, Zibouche N and Heine T 2011 Phys. Rev. B 83245213

[8] Tang Q and Zhou Z 2013 Prog. Mater. Sci. 581244

[9] Wang Q H, Zadeh K K, Kis A, Coleman J N and Strano M S 2012 Nat. Nanotechnol. 7699

[10] Radisavljevic B, Radenovic A, Brivio J, Giacometti V and Kis A 2011 Nat. Nanotechnol. 6147

[11] Chang K and Chen W 2011 ACS Nano 54720

[12] Britnell L, Ribeiro R M, Eckmann A, Jalil R, Belle B D, Mishchenko A et al 2013 Science 3401311

[13] Shanmugam M, Bansal T, Durcan C A and Yu B 2012 12th IEEE International Conference on Nanotechnology (IEEENANO)

[14] Zong X, Wu G, Yan H, Ma G, Shi J, Wen F et al 2010 J. Phys. Chem. C 1141963

[15] Xiang Q, Yu J and Jaroniec M 2012 J. Am. Chem. Soc. 1346575

[16] Dalrymple B J, Mroczkowski S and Prober D E 1986 J. Cryst. Growth $\mathbf{7 4} 575$

[17] Hofmann W K, Lewerenz H J and Petienkofer C 1988 Solar Energy Mater. 17165

[18] Xu K, Wang F, Wang Z, Zhan X, Wang Q, Cheng Z et al 2014 ACS Nano 88468

[19] Tan C, Zhao W, Chaturvedi A, Fei Z, Zeng Z, Chen J et al 2016 Small 121866

[20] Tedstone A A, Lewis D J and O'Brien P 2016 Chem. Mater. 281965
[21] Zhang Y, Liu K, Wang F, Shifa T A, Wen Y, Wang F et al 2017 Nanoscale 95641

[22] Rao C N R and Nag A 2010 Eur. J. Inorg. Chem. 20104244

[23] Matte H S S R, Gomathi A, Manna A K, Late D J, Datta R, Pati S K et al 2010 Angew. Chem. 1224153

[24] Deepak F L, Mayoral A and Yacaman M J 2009 Mater. Chem. Phys. 118392

[25] Duan X, Wang C, Shaw J C, Cheng R, Chen Y et al 2014 Nat. Nanotechnol. 91024

[26] Tongay S, Fan W, Kang J, Park J, Koldemir U, Suh J et al 2014 Nano Lett. 143185

[27] Pourabbas B and Jamshidi B 2008 Chem. Eng. J. 13855

[28] Momma K and Izumi F 2011 J. Appl. Crystallogr. 441272

[29] Chetia L, Kalita D and Ahmed G A 2017 J. Photochem. Photobiol. 338134

[30] Kumar R, Verzhbitskiy I and Eda G 2015 IEEE J. Quant. Electron. 511

[31] Carvalho A, Ribeiro R M and Neto A H C 2013 Phys. Rev. B 88115205

[32] Zhao W, Ribeiro R M and Eda G 2015 Acc. Chem. Res. 4891

[33] Makama A B, Salmiaton A, Saion E B, Choong T S Y and Abdullah N 2016 Int. J. Photoenergy 20162947510

[34] Frasco M F and Chaniotakis N 2009 Sensors 97266

[35] Chavez C A, Antonio J A T and Jacome M A C ISBN: 978-953307-967-7 InTech, Available from: http://www.intechopen.com/books/x-ray-spectroscopy/chemical-quantification-ofmo-s-w-si-and-ti- v-by-energydispersive- $\mathrm{x}$-ray-spectroscopy

[36] Frey G L, Tenne R, Matthews M J, Dresselhaus M S and Dresselhaus G 1990 Phys. Rev. B 602883

[37] Zhang X, Han W P, Wu J B, Milana S, Lu Y, Li Q Q et al 2013 Phys. Rev. B 87115413

[38] Li H, Zhang Q, Yap C R, Tay B K, Edwin T H T et al 2012 Adv. Funct. Mater. 221385

[39] Gfroerer T H 2000 Luminescent materials and applications (Chichester: John Wiley \& Sons Ltd) 9209 